\title{
"How dare you?!": A self-verification perspective on how performance influences the effects of abusive supervision on job embeddedness and subsequent turnover
}

\author{
Troy A. Smith ${ }^{1}$ (1) | Artemis Boulamatsi ${ }^{2}$ (1) | Nikolaos Dimotakis ${ }^{3}$ \\ Bennett J. Tepper $^{4}$ | Blake A. Runnalls ${ }^{5}$ | Christopher S. Reina ${ }^{6}$ \\ Lorenzo Lucianetti ${ }^{7}$ \\ ${ }^{1}$ Department of Management, College of Business, University of Nebraska-Lincoln, Lincoln, Nebraska, USA \\ ${ }^{2}$ Department of Management, G. Brint Ryan College of Business, University of North Texas, Denton, Texas, USA \\ ${ }^{3}$ Department of Management, Spears School of Business, Oklahoma State University, Stillwater, Oklahoma, USA \\ ${ }^{4}$ Department of Management \& Human Resources, Fisher College of Business, The Ohio State University, Columbus, Ohio, USA \\ ${ }^{5}$ Department of Marketing, College of Business, University of Nebraska-Lincoln, Lincoln, Nebraska, USA \\ ${ }^{6}$ Area of Management \& Entrepreneurship, School of Business, Virginia Commonwealth University, Richmond, Virginia, USA \\ ${ }^{7}$ Department of Management and Business Administration, University of Chieti and Pescara, Pescara, Italy
}

\section{Correspondence}

Artemis Boulamatsi, Department of Management, G. Brint Ryan College of Business, University of North Texas, 331B Business Leadership Building, Denton, TX 76201, USA.

Email:artemis.boulamatsi@unt.edu

Troy A. Smith and Artemis Boulamatsi contributed equally to this work.

\begin{abstract}
Higher-performing employees are extremely important to organizations due to their superior contribution to unit performance and vaulted value within their teams. In turn, they espouse higher work-specific self-worth (WSSW) evaluations that influence how they react to abusive supervision. Taking a self-verification perspective, we theoretically explain how performance (through WSSW) augments the aversive nature of abusive supervision, which in turn affects higher-performing employees' job embeddedness and subsequent decisions to quit their jobs. Across three field studies, our model is supported as we find that performance is positively related to WSSW, which magnifies the negative effects of abusive supervision on satisfaction. Consequently, we discover that as job performance (and in
\end{abstract}


turn self worth) increases, abusive supervision indirectly reduces job embeddedness and increases turnover through two forms of satisfaction. We expound upon how these findings contribute to both theory and practice.

\section{KEYWORDS}

abusive supervision, job embeddedness, job performance, satisfaction, self-worth, voluntary turnover

\section{1 | INTRODUCTION}

Higher performers are core sources of competitive advantages for organizations (Aguinis \& O'Boyle, 2014; Barney, 1991) as they achieve greater sales, provide superior services, and generate more products (Becker \& Huselid, 2006; Lepak \& Snell, 1999). They are also more central and visible within their teams and organizations (Call et al., 2015), as others seek to learn from and associate with them, elevating higher performers to "role model" status (Oldroyd \& Morris, 2012). Thus, higher-performing individuals are especially valuable contributors to the success of their units (Trevor et al., 2007), which is why organizational leaders invest disproportionate resources in hiring, developing, and retaining higher performers (Deloitte Human Capital, 2008). While turnover, in general, is organizationally costly (Allen et al., 2010), losing higher-performing employees is "disproportionately detrimental to organizational success" (Nyberg, 2010, p. 440), as it undermines organizational performance (Kwon \& Rupp, 2013). Thus, it is critical to understand what impacts higher performers' ${ }^{1}$ choice to leave their organizations (Nyberg, 2010).

In these decisions, employees' supervisors are generally prominent because they control the distribution of important resources (e.g., compensation, promotions, development opportunities; see French et al., 1959; Tepper, 2007), and their actions signal the relative value of each employee within their workgroups (Vogel \& Mitchell, 2017). Indeed, extensive research shows supervisors' behaviors strongly impact subordinates (Barrick et al., 2015; Chen et al., 2019; Chiaburu et al., 2014) - especially aversive behaviors such as abusive supervision (i.e., nonphysical, hostile behaviors displayed toward employees; Tepper, 2000). The impact of abusive supervision is largely believed to be negative amongst most employees (Mackey et al., 2017). However, it is unclear whether one's performance impacts how one responds from a turnover standpoint to abusive supervision. To understand the extent to which abusive supervision spurns employees to leave their organizations, it is important to recognize that such behaviors are subject to interpretation by the employees. To that end, we argue that employees' performance impacts the lens via which leaders' abusive behaviors are appraised and understood (Leary, 2006). In particular, we posit that job performance positively informs employees' work-specific self-worth (WSSW; i.e., one's feelings about oneself at work; Leary \& Baumeister, 2000; Neeman \& Harter, 1986), which acts as a "lens through which people perceive their worlds and organize their behavior" (Swann et al., 2004, p. 12), as well as forms expectations and preferences on how others should interact with them (Swann, 1983).

While the role of self worth as a lens is impactful, there is, unfortunately, less clarity on how it operates. Different theories provide competing predictions about how people with differing self worth perceptions might react to aversive leader behaviors. For instance, self-enhancement theory (SEnT; Allport, 1937; Hull, 1943) argues that all people view leaders' abusive interactions with antipathy, and its compensatory view argues that those espousing less self worth would perceive leaders' abusive interactions as especially aversive and unfavorable (De Cremer, 2003; Jones, 1973). In contrast, self-verification theory (SVT) argues that individuals desire to have their self-views (whether positive or negative) affirmed by important others - those that have "a firm basis from which to make a judgment" (Swann, 1983, p. 49; see also Hixon \& Swann, 1993). SVT further contests that when interactions with important others, such as supervisors, do not align with how someone expects to be treated as a result of their self-views, a self-verification crisis 
(i.e., lack of coherence) ensues (Swann, 1983; Webster \& Sobieszek, 1974). Thus, for higher-performing employees, encountering abusive supervision ${ }^{2}$ would likely be a negatively jarring experience as it disaffirms their sense of self, resulting in highly frustrating experiences.

SVT posits that self-verification experiences, in turn, impact employees' attitudes toward the context (i.e., job) and the leader that (dis)affirm their self-views (Lanaj et al., 2018; Swann, 1983; Talaifar \& Swann, 2020). This aligns with past research that indicates satisfaction with something or someone is a function of the match between what one wants or expects and what the context (job) or the person (leader) offers (see Locke, 1969). Therefore, when an individual with elevated self worth perceptions at work (e.g., higher performer) expects respectful supervisory treatment, they will be dissatisfied when the supervisor instead publicly ridicules and demeans (i.e., abuses) them, due to the lack of coherence experienced.

Importantly, satisfaction can, in turn, affect whether individuals leave the context in which they experience dissatisfying self-verification interactions as a means of protecting their self-views from being further disaffirmed (Cast \& Burke, 2002; Swann, 2005). As such, studies of employees' self-verification (or lack thereof) shed important light on the turnover processes of employees of varying performance levels. Therefore, we explore how satisfaction with one's job (Study 1) and leader (Studies 2 and 3) explain the indirect effect between self-verification experiences instigated by leaders' abusive supervision (among higher performers) and employees' job embeddedness (i.e., assessment of why people stay in their organizations [Crossley et al., 2007; Mitchell et al., 2001]) and subsequent voluntary turnover.

Our research makes at least three contributions to the management literature. First, we resolve extant theoretical tension between theories with opposing predictions on how individuals with varying levels of self worth - due to their job performance - respond to abusive supervision (Ferris, et al., 2015; Mayer et al., 2012). Specifically, compensatory SEnT argues that everyone reacts negatively to abusive supervision (Shrauger, 1975), with those espousing less self worth being particularly dissatisfied as they have an especially strong desire for positive interactions that compensate for their lower self-views (De Cremer, 2003; Jones, 1973; Leary \& Baumeister, 2000). Inversely, SVT posits that people prefer interactions that affirm their self-views, whether positive or negative (Swann, 1983). In other words, people with more self worth will be especially dissatisfied with leader abuse, while those with less self worth will be more tolerant of (and possibly even satisfied with) leader abuse because, to a degree, it affirms their existing self-concept (Talaifar \& Swann, 2020). Hollenbeck (2008) argues that resolving the lack of consensus between opposing theories is theoretically and practically urgent, because conflicting perspectives preclude organizational scholars from accurately informing practitioners how to effectively manage their employees, especially when both perspectives have empirically been supported across various domains and disciplines (Kwang \& Swann et al., 2010; Mackey et al., 2017; Swann et al., 1989). We contribute to the debate by testing the pattern that arises when employees with different self-views are abused by their supervisors and by revealing an antecedent that drives such differentiation.

Second, by integrating the active appraisal perspectives with SVT, we explain how self worth plays a key role in understanding the distinct effects of leaders' abuse on whether higher performers leave their organizations. Neither theory by itself explains why employees exhibiting differing levels of performance respond distinctly to abusive supervision. However, our integrated model expands our understanding of self-verification in the workplace. At its core, SVT focuses on self-views as a moderator that impacts how people react to interactions with important others in their lives (Swann, 1983). By leveraging active appraisal perspectives, we theorize that employees develop unique levels of self worth at work due to their job performance, which facilitates self-verification experiences as they interact with their leaders. Thereby, we enrich SVT by explaining and providing evidence of the precursors of self-verification experiences when employees confront abusive leaders, highlighting that employees' own behaviors at work (i.e., job performance) impact self-verification experiences by influencing their self worth. Thus, we show that individuals' self worth is a product of their behaviors, not just who they are or their contextual experiences (Ferris et al., 2012; Vogel \& Mitchell, 2017).

Finally, we provide a greater understanding of the determinants of why higher performers leave their organizations, which is detrimental to organizational success (Call et al., 2015; Nyberg, 2010). By integrating an active appraisal perspective with SVT, we propose that, via WSSW, higher and lower performers display differential turnover responses to abusive supervision (see Figure 1). These findings challenge the dominant consensus that abusive supervision has 


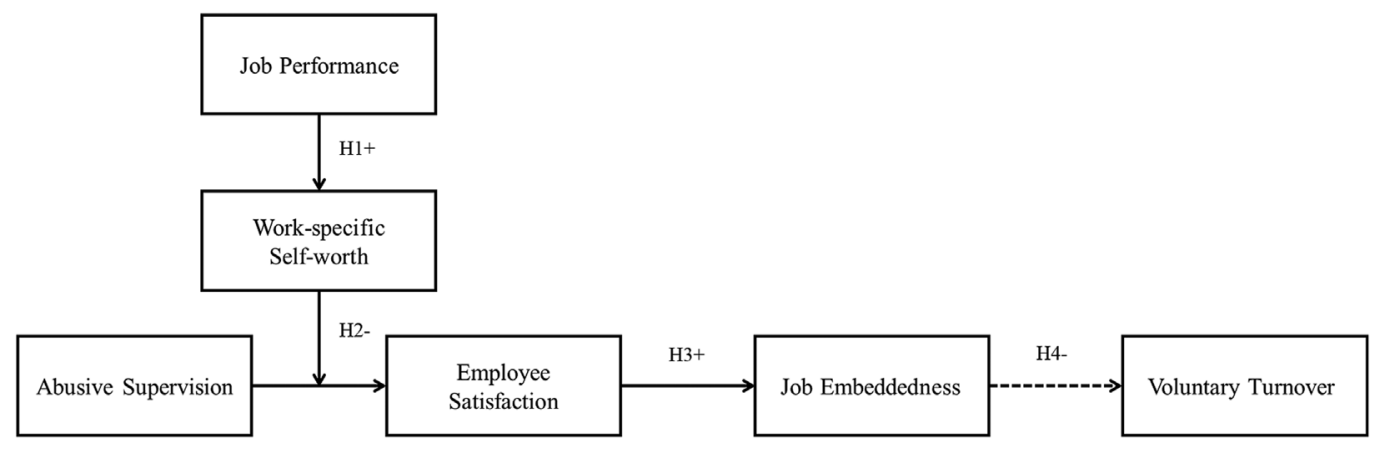

FIGURE 1 Proposed conceptual model.

Note. $\mathrm{H}=$ Hypothesis. $\mathrm{H} 2$ represents mediated moderation effects, and $\mathrm{H} 3$ and $\mathrm{H} 4$ represent moderated mediation effects. Solid lines represent the relationships tested in Studies 1-3; dotted line represents the relationship tested in Study 3

largely deleterious effects on satisfaction at work. Therefore, we add greater nuance to our understanding of this relationship by displaying how individual's behaviors and self-concepts influence the relationship between abuse and satisfaction (which was previously only attributed to cross-cultural contextual factors; Kernan et al., 2011; Lin et al., 2013). This confronts the theoretical perceptions of responses to abuse being largely negative within a given context, thus shifting the consensus by revealing a more person-focused view of the phenomenon (Hollenbeck, 2008). This is impactful because SVT indicates that the effects of abuse are even more potent among organizations' most valuable human assets (i.e., higher-performing employees), enhancing the risk of allowing abusive supervision to occur in highperformance or mission-critical contexts (Kwon \& Rupp, 2013; Nyberg, 2010; Trevor et al., 2007).

\section{2 | THEORY AND HYPOTHESES DEVELOPMENT}

\section{1 | Job performance and WSSW}

Self-views are important because they influence how individuals understand (and respond to) their contexts (Swann, 1983). It is thus critical to know how such views emerge, with the most proximal place being one's behaviors (Barkow, 1980). Along those lines, it has been proposed that self worth ${ }^{3}$ "is tied to the value or quality of [one's] actions" (Mruk, 2006; p. 29), though such views have largely not been integrated within the extant organizational literature. However, this perspective provides important insights. Indeed, as actions can vary across contexts, individuals can have different levels of self worth across those contexts (Marsh, 1993; Marsh et al., 2006). Specific to the work context, the most relevant self-view is work-specific self worth (Barkow, 1980; Leary, 2006; Solomon et al., 1991).

The integration of the active appraisal perspectives (Leary, 2006) and SVT (Swann, 1983) sheds light on the role that WSSW plays in explaining why individuals that display higher levels of performance leave their organizations when they encounter abusive supervision. Active appraisal perspectives (Leary \& Baumeister, 2000; Leary \& Downs, 1995) argue that self worth is part of a process through which individuals actively strive to appraise their social, cultural, or interpersonal standing (Leary, 2006), because self worth reflects one's value (Solomon et al., 1991), status (Barkow, 1980), and acceptance (Leary \& Downs, 1995) within a social entity. Therefore, in line with active appraisal perspectives, employees' job performance is likely to enhance their WSSW in three ways (Leary, 2006).

First, domain-specific self worth is enhanced when individuals' behaviors within that domain (Mruk, 2006) lead them to view themselves as possessing greater value in that domain (Solomon et al., 1991). Job performance behaviors certainly fit that description as higher performers achieve greater sales, generate more products, provide better 
service, and so forth, leading them to "bring substantial" (Campbell et al., 2017, p. 845), even "disproportionate organizational value" (Call et al., 2015, p. 623) to their units. In fact, employees at the top of the performance distribution are "many times more valuable than their lower-performing colleagues" (Cole \& Cole, 1973; Ernst et al., 2000). This is especially salient for employees because knowledge about performance disseminates quickly across organizational settings (Molleman et al., 2007), allowing employees to recognize their organizational value as they see how their performance contributes to their units' success. Beyond that, organizations that implement performance-based compensation structures are likely to provide higher-performing employees with more financial benefits (e.g., bonuses and pay increases), which is a signal of organizational value (Swann, 2005) that propels greater WSSW.

Second, job performance impacts employees' self worth perceptions at work by elevating their perceived status and influence in their organizations. As performance increases, individuals possess greater competence and expert status in their units (Bandura, 1990; Ericsson \& Lehmann, 1996), allowing them to be more dominant contributors to their units' success (Trevor et al., 2007). Indeed, Call et al. (2015) argue that as individuals' performance increases, they wield broader influence on organizational decisions (see Tzabbar, 2009). As a result, the elevated status and influence that higher-performing employees possess enhance their self worth at work.

Third, performance can impact self worth by enhancing individuals' perceived acceptance at work (Leary, 2006), because the more support and approval people experience, the better they feel about themselves (Harter, 1993). Thus, as performance increases, employees' heightened contributions provide them with greater job security (Call et al., 2015) and internal promotion opportunities (Peter \& Hull, 1969); both of which signal organizational support and approval of the employees (Leary, 1990). Indeed, prior research supports our arguments, as a longitudinal study conducted by Marsh et al. (1999) shows that academic performance leads to greater academic-specific self worth evaluations ${ }^{4}$. In turn, we propose:

Hypothesis 1: Job performance is positively related to employee WSSW.

\subsection{Abusive supervision and self-verification}

Abusive supervision, unsurprisingly, is theoretically expected to be negatively associated with satisfaction at work, generally defined (Mackey et al., 2017; Tepper, 2000). For the typical employee, abusive supervision is an aversive experience that generally is not reflective of a match between desired and experienced treatment or states (Locke, 1969; see Kernan et al., 2011 for an exception). Prior empirical evidence on abusive supervision is more in line with SEnT, which assumes that aversive leader interactions largely result in negative employee reactions because employees desire positive, self-enhancing leader interactions (De Cremer, 2003; Mackey et al., 2017). However, this theoretical viewpoint is unable to explain why some employees might have stronger or weaker (or even null) reactions to aversive experiences. We thus use an SVT perspective to understand this potential differentiation and expand our knowledge of employee responses to abusive supervision. Essentially, by integrating SVT and active appraisal perspectives (Barkow, 1980; Leary \& Baumeister, 2000; Solomon et al., 1991), we are able to explain how and why job performance might indirectly moderate the relationship between abuse and satisfaction via employees' WSSW. This occurs because individuals' self-views influence how they desire and expect to be treated by important others (Swann \& Brooks, 2012; Swann et al., 2004), influencing how satisfied they are by experienced interactions. Indeed, prior SVT research demonstrates that satisfaction is a proximal outcome of self-verification experiences at work (Cable \& Kay, 2012; Thatcher \& Zhu, 2006) and nonwork domains (Burke \& Stets, 1999; Katz et al., 1996; Kwang \& Swann, 2010).

SVT argues that individuals' strong desire for coherence makes them prefer self-verifying interactions with others who are in positions to make sound judgments (i.e., leaders) to affirm their perceptions of reality with regard to their self-views (Swann, 1983). To the extent that leaders' interactions match employees' expectations of how they 
perceive they should be treated based upon their self worth at work, employees experience continuity and coherence, thus increasing their satisfaction with the context and leader (Swann, 1983; Swann \& Buhrmester, 2012). Such arguments are in line with related viewpoints that satisfaction is an attitudinal byproduct of receiving what one wants or expects from one's job or leader (Locke, 1969; Porter \& Steers, 1973; Steers \& Mowday, 1981). On the contrary, interactions that disaffirm expectations clash with the individual's view of how the world should be, creating an unpleasant and confusing context, rendering the interactions dissatisfying (see Cable \& Kay, 2012; Sacco \& Phares, 2001; Swann, 2005). This is because the unexpected leader behavior is a shock to the employees' perceived reality and the ensuing lack of coherence results in feelings of threat, distress (Ayduk et al., 2011), and the psychological and affective "equivalents of tidal waves" (Swann \& Buhrmester, 2012, p. 407).

Thus, while hedonic viewpoints argue that individuals simply seek pleasurable experiences and avoid painful ones (Higgins, 1997; Vroom, 1964), SVT takes a more nuanced view of what individuals find tolerable or aversive. In the case of abusive supervision, SVT suggests that as individuals' WSSW increases because of increasing job performance, the more leaders' abusive behaviors contradict the individuals' increasing expectations to be treated respectfully or favorably. The lack of coherence between how higher-performing employees view themselves and the leaders' treatment of them, subsequently engenders greater dissatisfaction toward the disaffirming context (job) and individual providing the disaffirming interaction (leader), because the interactions increasingly oppose their positive self-perceived reality (Cable \& Kay, 2012; De La Ronde \& Swann, 1998; Ritts \& Stein, 1995).

In sum, being that performance levels are likely positively related to WSSW (Bandura, 1990; Tracy \& Robbins, 2004), as performance increases, employees have higher expectations of being treated with greater respect and dignity by their supervisors, as befits their increasingly elevated perceived worth at work. However, the inherently aversive nature of being yelled at, demeaned, or openly criticized "undermines their sense of value and worth to the workgroup" (Vogel \& Mitchell, 2017, p. 2221), contradicting their positive interaction expectations tied to their vaulted self worth views at work. As the dissonance becomes greater between how they perceive they should be treated and their perception of being abused by their leader, employees experience more dissatisfaction in their job and with the supervisor. Thus, we propose:

Hypothesis 2: Job performance indirectly moderates, via WSSW, the negative relationship between abusive supervision and satisfaction, such that this relationship will be more negative at higher (vs. lower) levels of performance.

The dissatisfaction that results from disaffirming interactions with one's leader can be associated with different outcomes, as such attitudes have been argued to be linked to multiple perceptual and behavioral outcomes (Schleicher et al., 2015; Scott \& Taylor, 1985). SVT suggests that when individuals' self-views are disaffirmed by an important other, they try to resolve the dissatisfying experience by acting in a self-verifying manner to persuade the important other to treat them in self-affirming ways (e.g., as individuals' self-views increase, when they are abused, they may attempt to improve their performance to garner respect from their leader; Swann, 1983). However, as individuals' performance rises, they are increasingly limited in how much they can enhance their performance by a ceiling effect (Brockner, 1988; Chen et al., 2019) they face due to already engaging in vaulted levels of performance. As a result, there is limited opportunity (or capacity) for any meaningful performance enhancement. Thus, they perceive they cannot engage in sufficiently higher than higher performance levels to persuade their supervisors to treat them in a self-affirming, respectful manner.

Therefore, individuals experiencing disaffirming interactions may not be able to change how their leaders interact with them. In turn, SVT research suggests that the increased dissatisfaction resulting from disaffirming interactions will render the context more aversive to the individual, reducing one's reasons to stay in the organization (e.g., job embeddedness). To that end, Swann and Hill (1982) indicate that when individuals' enhanced efforts cannot alter how disaffirming actors interact with them, they have fewer reasons to stay within the context where their self worth is 
consistently disaffirmed. Indeed, individuals who experience disaffirming interactions in other life domains are more likely to end relationships with the offending actors (Cast \& Burke, 2002; Kwang \& Swann, 2010). In the workplace, therefore, as performance increases, employees will have fewer reasons to stay in a context where their heightened self worth is disaffirmed by their leader's abusive actions (Swann \& Buhrmeister, 2012). This is especially the case for higher-performing employees because they have greater job mobility (Call et al., 2015).

Thus, we propose that the interaction of abusive supervision and WSSW (due to performance) will indirectly impact job embeddedness (Crossley et al., 2007; Hom et al., 2012; Lee et al., 2014) via satisfaction processes. Job embeddedness entails three underlying facets for why people stay in their organizations, which include: (1) fit (employees' compatibility between work and life spaces), (2) links (the formal or informal links that people have with institutions or other people), and (3) sacrifice (the material or psychological benefits or losses associated to leaving one's job or community; Crossley et al., 2007; Lee et al., 2014).

Adopting an SVT perspective, we argue that satisfaction due to self-verifying interactions is positively related to each of the embeddedness facets. First, employees desire interactions at work to be compatible with their self-views (Kristof-Brown et al., 2005). Thus, the satisfaction employees experience when leaders affirm the employees' selfviews enhances their job embeddedness fit. Second, satisfied employees are more willing to invest their time and energy into creating higher quality connections or relationships with their colleagues (Volmer et al., 2011), strengthening job embeddedness linkages. Finally, because people have strong preferences for interactions that verify their self-views, the satisfaction they experience when leaders affirm their self-views is a desirable facet of work (Swann \& Buhrmester, 2012) that would be sacrificed by leaving their organizations. Extant empirical evidence supports the notion that employees who encounter disaffirming interactions are less likely to stay in the context where dissatisfying interactions occur (Cast \& Burke, 2002; De La Ronde \& Swann, 1998; Swann \& Buhrmester, 2012; Swann et al., 2002). Thus, we propose:

Hypothesis 3: Job performance indirectly moderates, via WSSW, the negative indirect effect of abusive supervision on employee job embeddedness via satisfaction, such that this indirect effect will be more negative at higher (vs. lower) levels of performance.

\section{3 | STUDY 1 METHODS}

\section{1 | Sample and procedure}

Participants were full-time employees in a theme park located in the southern United States. Data were collected online in 2019 through two surveys (Institutional Review Board [IRB] protocol from Georgia State University. Title: "Field examination of veteran peers' perceptions and reactions to high status and proactive newcomers," IRB \#H18592). The Time 1 survey (T1) included: abusive supervision, job performance, WSSW, and demographics. The Time 2 survey (T2), given a month later, included job satisfaction and job embeddedness.

A total of 1,276 employees were invited to take the surveys. We received 344 complete responses (response rate $27 \%$ ) in T1. T2 responses were 126, for a retention rate of $37 \%$. Due to sample and context concerns (e.g., high variance in seasonal and regular employment, education level, age, and work responsibilities, which together created compliance concerns), individuals were asked to complete the survey in one session. More specifically, participants were not allowed to return to the survey and complete it at a later date. As such, we excluded 142 responses from T1 in which participants left their surveys idle ${ }^{5}$, an indication of noncompliance with instructions. We used FIML to account for missing dependent variables in the analyses, resulting in a final sample size of 202 employees. Employees were mostly female (53.5\%) and White (92\%). On average, they were 49 years old $(S D=17.3)$ and had 4.4 years $(S D=5.2)$ in the organization. About $57 \%$ had a college degree and $41 \%$ had a high-school diploma. 


\subsection{1 | Measures}

All scales were measured on a 5-point Likert scale ( 1 = strongly disagree, $5=$ strongly agree).

Abusive supervision. Similar to past abusive supervision research (McClean et al., 2021), employees were asked to respond to five items (e.g., "My supervisor tells me my thoughts or feelings are stupid") focused on their leader's abusive supervision (Mitchell \& Ambrose, 2007).

Job performance. Employees rated their job performance (e.g., "I fulfill the responsibilities specified in my job description") with a four-item scale derived from Williams and Anderson (1991).

Work-specific self worth ${ }^{6}$. We adapted the six items that were developed by Neeman and Harter (1986) and validated by Masciuch et al. (1990) to capture work-specific self-worth by inserting "at work" in each item. Employees rated their agreement with each item. Sample items are "I like the kind of person I am at work" and "I am usually satisfied with myself at work."

Job satisfaction. We operationalized satisfaction at work by measuring job satisfaction, because in an organizational context satisfaction with one's job is a core outcome of self-verification experiences (Judge et al., 2000). Employees rated their agreement with three statements describing their current satisfaction towards their job (see Tepper et al., 2009). A sample item is "All in all, I like working at my job."

Job embeddedness. Employees rated the seven items (e.g., "I feel tied to this organization") developed by Crossley et al. (2007) to capture job embeddedness.

Controls $^{7}$. We controlled for employees' negative affect, which is theoretically relevant because negative affect influences how people react to abuse (e.g., Tepper, et al., 2009). We measured negative affect with a five-item PANAs scale (Merz et al., 2013).

\subsubsection{Analyses}

We used FIML estimation path modeling in Mplus 8, because FIML yields unbiased estimates and is more efficient than other alternatives (Enders \& Bandalos, 2001). We calculated confidence intervals using parametric estimates (Preacher \& Selig, 2012) in R, using 20,000 replications. In the path model, job performance predicted WSSW (Hypothesis 1). Abusive supervision, job performance, WSSW, and their interactions were used as predictors of job satisfaction (Hypothesis 2). Job satisfaction was then used to predict job embeddedness (controlling for the effects of abusive supervision, job performance, and WSSW; Hypothesis 3). Across all models, negative affect was used as a control.

We followed the Edwards and Lambert (2007) procedure adapted to predict an effect on a slope as opposed to on an outcome variable. That is, we concurrently established the effect of job performance (JP) on WSSW, and subsequently tested the moderating effect of WSSW on the relationship between abusive supervision (AS) and job satisfaction (JS; controlling for the direct effects of abusive supervision and the interaction of abusive supervision and job performance). The formulation of these analyses mirrors a typical indirect effect. Specifically, we first predict WSSW from job performance:

$$
\text { WSSW }=a_{0}+a_{1} \mathrm{JP}
$$

We then predicted job satisfaction from abusive supervision, job performance, WSSW, and the interaction between abusive supervision and job performance and the interaction between abusive supervision and WSSW.

$$
\begin{aligned}
\mathrm{JS}= & b_{0}+b_{1} \mathrm{AS}+b_{2} \mathrm{JP}+b_{3} \mathrm{WSSW} \\
& +b_{4} \mathrm{AS} * \mathrm{JP}+b_{5} \mathrm{AS} * \mathrm{WSSW}
\end{aligned}
$$


TAB LE 1 Descriptive statistics and correlations (Study 1)

\begin{tabular}{|c|c|c|c|c|c|c|c|c|c|}
\hline & & $M$ & $S D$ & 1 & 2 & 3 & 4 & 5 & 6 \\
\hline 1. & Negative affect (T2) & 1.52 & 0.53 & $(.58)$ & & & & & \\
\hline 2. & Abusive supervision (T1) & 1.58 & 0.96 & .36 & $(.96)$ & & & & \\
\hline 3. & Job performance (T1) & 4.67 & 0.70 & -.22 & -.23 & $(.95)$ & & & \\
\hline 4. & Self-worth (T1) & 4.36 & 0.63 & -.42 & -.21 & .29 & (.86) & & \\
\hline 5. & Job satisfaction (T2) & 4.42 & 0.92 & -.31 & -.17 & -.07 & .37 & $(.94)$ & \\
\hline 6. & Job embeddedness (T2) & 3.27 & 1.10 & -.06 & -.16 & -.26 & .07 & .67 & (.93) \\
\hline
\end{tabular}

Note. $N=202$. Correlations greater than or equal to $|.13|$ are significant at $p<.10$; those greater than or equal to $|.14|$ are significant at $p<.05$; those greater than or equal to $|.19|$ are significant at $p<.01$. T1 and T2 refer to Time 1 and Time 2 measures, respectively. Alpha reliabilities of the scales are in parentheses on the diagonal.

Substituting Equation (1) into Equation (2) gives the indirect moderation effect as $a_{1}{ }^{*} b_{5}$, which is interpreted as the indirect effect of job performance (via WSSW) on the conditional relationship between abusive supervision and job satisfaction. Simply put, the moderating effect of job performance occurs through its effects on WSSW. Finally, we calculated ${ }^{8}$ parametric estimates (and confidence intervals of the same) of the indirect effects of abusive supervision through job satisfaction on job embeddedness across all observed values of job performance (Johnson \& Neyman, 1936) to test Hypothesis 2 and 3. All predictor variables were centered prior to inclusion in the model.

\section{2 | Results}

First, we conducted a series of CFAs using Mplus 8 to establish construct and discriminant validity. The hypothesized 6-factor model (i.e., abusive supervision, WSSW, job performance, job satisfaction, job embeddedness, and negative affect) showed acceptable fit $\left(\chi^{2}{ }_{(390)}=667.57, p=.00 ; \mathrm{CFI}=.92\right.$; TLI $=.92$; SRMR $=.11$; RMSEA $=.06$, $\left.\mathrm{Cl}_{95 \%}=.05, .07\right)$. Alternative models ${ }^{9}$ uniting performance with self worth, and job satisfaction with embeddedness showed worse fit $\left(\Delta \chi^{2}=775.81, \Delta \mathrm{df}=5, p=.00 ; \Delta \chi^{2}=98.51, \Delta \mathrm{df}=5, p=.00\right.$, respectively), supporting the hypothesized factor structure. In sum, the proposed model adequately fit the data (Williams \& O'Boyle, 2008; Williams et al., 2020).

Table 1 shows means, standard deviations, alpha reliabilities, and correlations among the variables included in this study. Table 2 shows the results of the path model testing our hypotheses, showing that our overall model demonstrated adequate fit to the data $\left(\chi^{2}{ }_{(4)}=2.80, p=.59 ; \mathrm{CFI}=1.00 ; \mathrm{TLI}=1.00 ; \mathrm{SRMR}=.02 ; \mathrm{RMSEA}=.00, \mathrm{Cl} 95 \%=.00\right.$, .09). Job performance had a significant positive effect on self worth ( $b=.18, p=.02)$, supporting Hypothesis 1 . Next, we tested the moderating role of self worth on the relationship between abusive supervision and job satisfaction, controlling for negative affect, job performance, and the interaction of abusive supervision and job performance. Results showed that self worth is a significant moderator $(b=-.48, p=.00$; see Figure 2$)$, such that the negative effects of abusive supervision were more strongly negative for higher self worth employees relative to lower self worth employees. The indirect moderating effect of job performance through self worth on the relationship between abusive supervision and job satisfaction was indeed significant and in the expected direction (IE $\left.=-.09, \mathrm{Cl}_{95 \%}=-.21,-.02\right)$. Specifically, the slope of abusive supervision for higher ${ }^{10}$ performers (through self worth) was significantly negative $(b=-.21$, $p=.02$ ), while not significant for lower performers $(b=-.13, p=.15)$, supporting Hypothesis 2 . The two slopes were statistically different (diff $=-.08, \mathrm{Cl}_{95 \%}=-.19,-.02$ ).

Finally, we tested the effect of job satisfaction on job embeddedness controlling for abusive supervision, job performance, self worth, and negative affect to compute the hypothesized indirect effects. Results indicated that job 
TABLE 2 Path model output (Study 1)

\begin{tabular}{|c|c|c|c|c|c|c|}
\hline & \multicolumn{2}{|c|}{ Self-worth } & \multicolumn{2}{|c|}{ Job satisfaction } & \multicolumn{2}{|c|}{ Job embeddedness } \\
\hline & $B(S E)$ & $\beta$ & $B(S E)$ & $\beta$ & $B(S E)$ & $\beta$ \\
\hline \multicolumn{7}{|l|}{ Controls } \\
\hline Negative affect & $-.45^{* *}(.11)$ & -.39 & $-.24(.19)$ & -.14 & $.25(.19)$ & .12 \\
\hline \multicolumn{7}{|l|}{ Study variables } \\
\hline Abusive supervision & & & $-.19^{*}(.09)$ & -.20 & $-.17^{\dagger}(.09)$ & -.14 \\
\hline Job performance & $.18^{*}(.08)$ & .21 & $-.60^{*}(.25)$ & -.45 & $-.28^{\dagger}(.16)$ & -.17 \\
\hline Self-worth & & & $.57^{* *}(.17)$ & .38 & $-.23(.18)$ & -.12 \\
\hline Abusive supervision $\times$ job performance & & & $.16(.16)$ & .14 & & \\
\hline Abusive supervision $\times$ self-worth & & & $-.48^{* *}(.15)$ & -.31 & & \\
\hline Job satisfaction & & & & & $.86^{* *}(.11)$ & .70 \\
\hline$R^{2}$ & .23 & & .36 & & .56 & \\
\hline
\end{tabular}

Note. $N=202$. All independent variables in the models were grand-mean centered. $B=$ unstandardized coefficients; $S E=$ standard errors; $\beta=$ standardized coefficients.

${ }^{\dagger} p<.10 ;{ }^{*} p<.05 ;{ }^{* *} p<.01$, two-tailed tests.

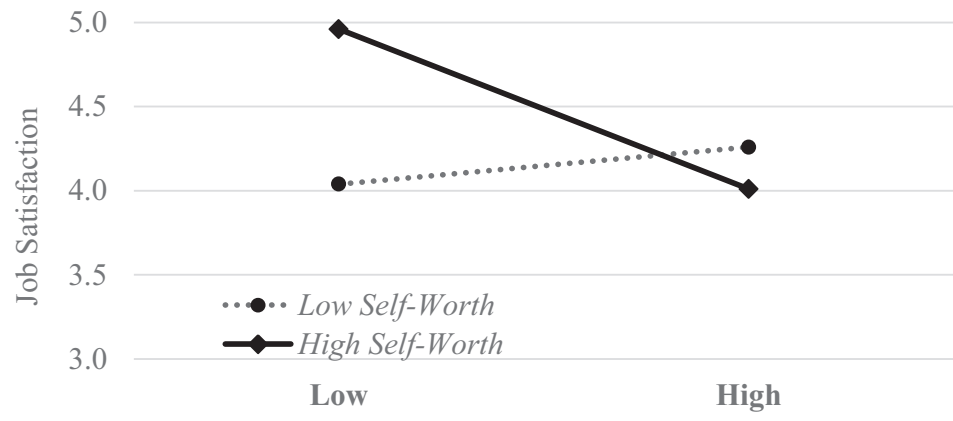

FIGURE 2 Interaction of abusive supervision and self-worth on job satisfaction (Study 1)

Abusive Supervision

satisfaction positively impacted job embeddedness $(b=.86, p=.00)$. Overall, the conditional indirect effect of abuse on job embeddedness for higher performers (defined as above) was significantly negative (IE $=-.18, C l_{95 \%}=-.37$, -.03), while the effect for lower performers was not different from zero (IE $\left.=-.12, C_{95 \%}=-.29, .04\right)$. More specifically, results following the Johnson and Neyman (1936) approach show that the slope of abusive supervision is significant for job performance at levels of .2 SDs below the mean and above (corresponding to values of 4.53 and upward). For all other employees, the indirect effects were nonsignificant. A supplemental analysis displayed that the conditional indirect effects were significantly different from each other (diff $=-.07, \mathrm{Cl}_{95 \%}=-.17,-.02$ ), supporting Hypothesis 3.

\subsection{Study 1 discussion}

The data support our hypotheses that job performance is associated with individuals' WSSW, which in turn moderates the indirect effect of abusive supervision on job embeddedness via job satisfaction. These findings support active appraisal perspectives (Leary, 2006) by showing that job performance is positively related to WSSW. In addition, Study 1 informs self-verification views by showing that it is through WSSW that job performance impacts the indirect 
relationship between abusive supervision and job embeddedness via job satisfaction. In line with our hypotheses, abusive supervision disaffirms the elevated WSSW that higher performers espouse, leading to reduced job satisfaction and subsequent job embeddedness. In contrast, abuse is more tolerated as employees' performance decreases due to the deflating WSSW, mitigating the indirect effect that abuse has on job embeddedness through job satisfaction. A limitation of Study 1 is the low reliability of one control variable, negative affect. However, the conclusions remained unaffected when we excluded the controls from our hypothesized model.

Although these findings support our hypotheses, to strengthen our confidence in the validity and generalizability of our findings, we conducted a second study that allowed us to replicate Study 1 with two enhancements. First, we tested our model focusing on employees' satisfaction with their supervisors, rather than job satisfaction. Although past research has proposed and shown that job satisfaction is an outcome of self-verification experiences (Cable \& Kay, 2012), technically it is the supervisor - in the case of abusive supervision - that is (dis)affirming the employees' selfviews. Thus, we sought to assess whether satisfaction with the supervisor is a more proximal and specific mechanism through which the self-verification experience (i.e., abusive supervision interacts with job performance through self worth) impacts employees' job embeddedness. This is in line with past research on SVT that shows that self-verifying interactions in nonwork contexts are predictive of satisfaction in such contexts (Murray et al., 2000; Sacco \& Phares, 2001). Second, we control for competence uncertainty (i.e., one's certainty with regard to one's effectiveness, ability, and success in the workplace). Referring to the mixed findings between SVT and SEnT, Mayer et al. (2012) argue that the "inconsistent findings could be explained by considering the role of competence uncertainty" (p. 37). Beyond that, Mayer et al. (2012) showed that competence uncertainty is a known moderator of the relationship between leader mistreatment and counterproductive behaviors. In turn, it may impact the extent to which abusive supervision indirectly impacts employees' turnover decisions.

\section{4 | STUDY 2 METHODS}

\subsection{Sample and procedure}

Data were collected online in 2019 from full- and part-time student affairs employees at a university in the southern United States. (IRB protocol from the University of Nebraska - Lincoln. Title: "Leader-Subordinate Effectiveness in the Workplace", IRB\# 20170917328 EP) ${ }^{11}$. Participants, incentivized with a raffle (for $\$ 5-\$ 50$ gift cards), completed three surveys, each distributed with a 3-week lag. Participants' demographics were reported at Time 1 (T1), while they rated their leaders' abusive supervision and their own job performance at Time 2 (T2). At Time 3 (T3), they rated their WSSW, leader satisfaction, and job embeddedness. As work hours varied, average hours per week in the past month were reported in each survey.

Using organizational files, we invited 944 employees to participate in the study, with some of them being parttime employees. There were 499 employees that completed the T1 survey (response rate of 53\%). We followed past leadership research by only including those that reported working an average of at least 20 hours per week during the study (see Matta et al., 2015), resulting in 318 completed responses in T1. From there, 181 employees completed the T2 survey, and 207 employees completed the T3 survey. To improve our data quality, we followed past research (Rosen et al., 2020; Tepper et al., 2018) by adding an open-response question at the end of each survey, allowing employees to report any issues with the surveys. We excluded cases whose comments raised concern about the quality of the data ${ }^{12}$, resulting in a matched sample across the three surveys of 144 employees. Again, we used FIML for the analyses (Rubin \& Little, 2002), resulting in a final sample of 166 employees (52\% retention rate from T1). Employees were mostly female (67\%) and White (60\%), with $32 \%$ being part-time employees. On average, they were 35 years old (SD =13.4) and had an organizational tenure of $6.2(S D=8.6)$ years. About $68 \%$ had a college degree and $31 \%$ had a high-school diploma. 


\subsection{1 | Measures}

The Abusive Supervision, job satisfaction, WSSW, Job Embeddedness, and Negative Affect scales were measured as in Study 1.

Leader satisfaction. Participants were asked to use a 5-point Likert scale ( $1=$ strongly disagree, $5=$ strongly agree) to indicate their agreement towards three statements describing their current satisfaction towards their leader (see Tepper et al., 2009). A sample item is "All in all, I am satisfied with [leader name] as my leader."

Controls $^{13}$. As with Study 1, we controlled for employees' negative affect. We also controlled for a four-item scale of employee competence uncertainty ${ }^{14}$ (e.g., "I am uncertain whether I am competent") because competence uncertainty impacts how people react to leader mistreatment (Mayer et al., 2012). Finally, we used organizational records to create a dummy coded variable ${ }^{15}$ to account for differences in employment status (i.e., full- and part-time employees), because it is related to satisfaction and self worth (Sinacore-Guinn, 1998).

\subsubsection{Analyses}

Our analyses mirrored those of Study 1, with the exception of the added controls of competence uncertainty and employment status.

\section{2 | Results}

As in Study 1, we conducted a series of CFAs using Mplus 8. We examined the hypothesized seven-factor model (i.e., abusive supervision, self worth, job performance, leader satisfaction, job embeddedness, negative affect, and competence uncertainty). The model largely displayed adequate fit $\left(\chi^{2}{ }_{(506)}=1090.71, p=.00 ; \mathrm{CFI}=.87 ; \mathrm{TLI}=.86\right.$; SRMR $\left.=.08 ; \mathrm{RMSEA}=.08, \mathrm{Cl}_{95 \%}=.08, .09\right)$. Although the factor loadings, RMSEA, and SRMR show adequate fit, the CFI and TLI are under the desired cutoffs (Hu \& Bentler, 1999; Williams et al., 2020). However, fit indices can be hurt by larger models (West et al., 2012; Williams et al., 2020), as the one we have ${ }^{16}$. To improve the sample size to model size ratio and adopt a more holistic approach that does not strictly heed cutoffs but rather examines the model more comprehensively (Williams \& O'Boyle, 2008), we adopted a couple of different modeling strategies to reduce the number of estimated parameters in our model.

Following previous research and recommendations, we used two parceling approaches as supplemental tests of our model (Williams et al., 2020). We first employed a balancing approach (Little et al., 2013) for the scales including more than four items by pairing the item with the highest factor loading with the item with the lowest factor loading into one parcel and so forth. We used two parcels for each construct with two to five items in each parcel (e.g., Klotz et al., 2018). CFA results of the seven-factor model including all the study variables showed good model fit $\left(\chi^{2}(131)=228.33, p=.00\right.$; $\left.\mathrm{CFI}=.96 ; \mathrm{TLI}=.95 ; \mathrm{SRMR}=.05 ; \mathrm{RMSEA}=.07, \mathrm{Cl}_{95 \%}=.05, .08\right)$. Alternative models combining performance with self worth, and leader satisfaction with embeddedness showed worse fit $\left(\Delta \chi^{2}=253.57, \Delta \mathrm{df}=6, p=.00 ; \Delta \chi^{2}=200.77\right.$, $\Delta \mathrm{df}=6, p=.00$, respectively), supporting the hypothesized factor structure. Overall, these results suggest that the fit of the original model was indeed hurt by model size rather than construct issues. We also reran our parcels using random parcel assignment (e.g., Koopman et al., 2019). The model showed adequate fit $\left(\chi^{2}(131)=312.93, p=.00 ; C F I=.93\right.$; $\left.\mathrm{TLI}=.90 ; \mathrm{SRMR}=.06 ; \mathrm{RMSEA}=.09, \mathrm{Cl}_{95 \%}=.08, .11\right)$, further validating the goodness of fit of the data to the proposed measurement model. Thus, we tested our hypotheses ${ }^{17}$.

Table 3 shows means, standard deviations, alpha reliabilities, and correlations among the variables included in Study 2. Table 4 summarizes the results of our path model, showing that our overall model demonstrated adequate fit to the data $\left(\chi_{(4)}^{2}=5.12, p=.28 ; \mathrm{CFI}=.99 ; \mathrm{TLI}=.95 ; \mathrm{SRMR}=.02 ; \mathrm{RMSEA}=.04, \mathrm{Cl}_{95 \%}=.00, .13\right)$. 
TAB LE 3 Descriptive statistics and correlations (Study 2)

\begin{tabular}{|llrrrrrrrrrr|r|} 
& & $M$ & $S D$ & 1 & 2 & 3 & 4 & 5 & 6 & 7 & 8 \\
\hline 1. & Employment status & 1.32 & 0.47 & & & & & & & \\
\hline 2. & Negative affect (T2) & 1.84 & 0.95 & -.14 & $(.90)$ & & & & & \\
\hline 3. & Competence uncertainty (T3) & 1.48 & 0.76 & -.04 & .44 & $(.88)$ & & & & \\
\hline 4. & Abusive supervision (T2) & 1.26 & 0.55 & -.01 & .25 & -.02 & $(.94)$ & & & & \\
\hline 5. & Job performance (T2) & 4.49 & 0.49 & -.10 & -.11 & -.19 & -.07 & $(.93)$ & & \\
\hline 6. & Self-worth (T3) & 3.93 & 0.67 & .16 & -.47 & -.43 & -.12 & .29 & $(.92)$ & \\
\hline 7. & Leader satisfaction (T3) & 4.28 & 0.87 & .09 & -.25 & -.03 & -.52 & .06 & .26 & $(.91)$ \\
\hline 8. & Job embeddedness (T3) & 3.27 & 0.86 & -.11 & .02 & -.09 & .09 & .09 & .20 & .13 & $(.90)$ \\
\hline
\end{tabular}

Note. $N=166$. Correlations greater than or equal to $|.13|$ are significant at $p<.10$; those greater than or equal to $|.16|$ are significant at $p<.05$; those greater than or equal to $|.20|$ are significant at $p<.01$. Demographics were collected at Time 1, while the study variables were collected at Time 2 (T2) and Time 3 (T3). Employment status: $1=$ full-time employees and 2 = part-time employees. Alpha reliabilities of the scales are in parentheses on the diagonal.

TAB LE 4 Path model output (Study 2)

\begin{tabular}{|c|c|c|c|c|c|c|}
\hline & \multicolumn{2}{|c|}{ Self-worth } & \multicolumn{2}{|c|}{ Leader satisfaction } & \multicolumn{2}{|c|}{ Job embeddedness } \\
\hline & $B(S E)$ & $\beta$ & $B(S E)$ & $\beta$ & $B(S E)$ & $\beta$ \\
\hline \multicolumn{7}{|l|}{ Controls } \\
\hline Employment status & $.18^{\dagger}(.10)$ & .13 & $.07(.13)$ & .04 & $-.27^{\dagger}(.15)$ & -.15 \\
\hline Negative affect & $-.23^{* *}(.05)$ & -.32 & $-.04(.08)$ & -.04 & $.12(.09)$ & .14 \\
\hline Competence uncertainty & $-.22^{* *}(.07)$ & -.25 & $.09(.09)$ & .08 & $-.04(.10)$ & -.04 \\
\hline \multicolumn{7}{|l|}{ Study variables } \\
\hline Abusive supervision & & & $-.75^{* *}(.11)$ & -.48 & $.30^{*}(.14)$ & .19 \\
\hline Job performance & $.29^{* *}(.09)$ & .22 & $-.03(.12)$ & -.02 & $.02(.14)$ & .01 \\
\hline Self-worth & & & $.31^{* *}(.11)$ & .24 & $.30^{*}(.13)$ & .24 \\
\hline Abusive supervision $\times$ job performance & & & $-.01(.28)$ & -.003 & & \\
\hline Abusive supervision $\times$ self-worth & & & $-.40^{*}(.17)$ & -.20 & & \\
\hline Leader satisfaction & & & & & $.22^{*}(.09)$ & .22 \\
\hline$R^{2}$ & .34 & & .36 & & .12 & \\
\hline
\end{tabular}

Note. $N=166$. All independent variables in the models were grand-mean centered. $B=$ unstandardized coefficients; $S E=s t a n-$ dard errors; $\beta=$ standardized coefficients.

$p<.10 ;{ }^{*} p<.05 ;{ }^{* *} p<.01$, two-tailed tests.

We found that job performance had a significant positive effect on self worth $(b=.29, p=.00)$, supporting Hypothesis 1. We then tested the moderating role of self worth on the relationship between abusive supervision and leader satisfaction. Self worth was a significant moderator ( $b=-.40, p=.02$; see Figure 3$)$, such that the negative effect of abuse was more strongly negative for higher self worth versus lower self worth employees. We combined these effects to test for the indirect moderating effect of job performance through self worth on the relationship between abusive supervision and leader satisfaction; the indirect moderating effect was in the expected direction and significant (IE $\left.=-.12, \mathrm{Cl}_{95 \%}=-.29,-.02\right)$. For higher $(+1 \mathrm{SD})$ performers, the slope of abusive supervision was negative and significant $(b=-.83, p=.00)$, while being weaker for lower $(-1 S D)$ performers $(b=-.67, p=.00)$. Although the slopes differed significantly (diff $=-.16, \mathrm{Cl}_{95 \%}=-.39,-.03$ ), both indirect effects remained negative and significant across 


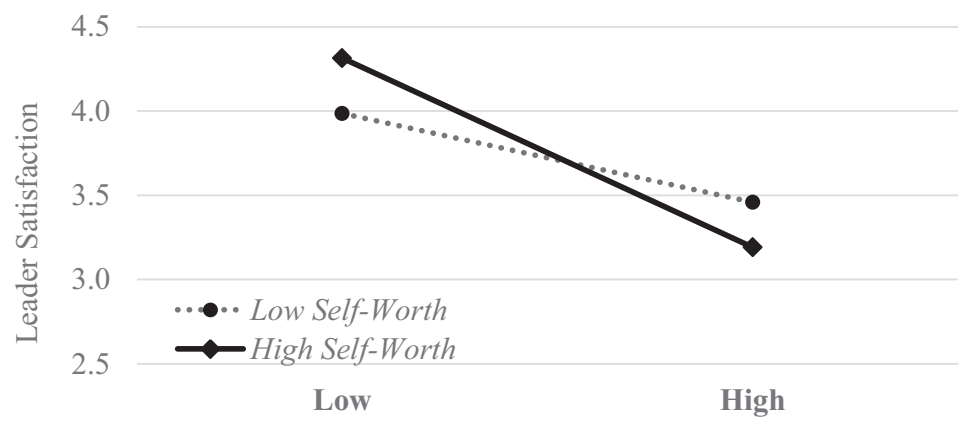

FIGURE 3 Interaction of abusive supervision and self-worth on leader satisfaction (Study 2)

Abusive Supervision

all moderator levels, due to the main effect of abusive supervision in these data being stronger for the more proximal mediator of leader satisfaction, compared to job satisfaction. Thus, Hypothesis 2 was supported.

We then tested the effect of leader satisfaction on job embeddedness. The path model shows that leader satisfaction was positively associated with job embeddedness $(b=.22, p=.02)$. The conditional indirect effect of abuse on job embeddedness for higher performers was significantly negative (IE $=-.18, \mathrm{Cl}_{95 \%}=-.36,-.03$ ), while the same effect was significantly weaker for lower performers ( $\left.I E=-.14, \mathrm{Cl}_{95 \%}=-.30,-.03\right)$. A supplemental analysis displayed that the conditional indirect effects were significantly different from each other (diff $=-.03, \mathrm{Cl}_{95 \%}=-.12,-.01$ ), which supports Hypothesis 3.

\section{3 | Study 2 discussion}

Study 2 strengthened the validity and generalizability of Study 1's findings by verifying that performance impacts employees' WSSW above and beyond their competence uncertainty, which in turn interacts with abusive supervision to impact its indirect effect on job embeddedness. In addition, Study 2 focused on a more precise mechanism (i.e., satisfaction with the leader) through which self-verification experiences impact employees' job embeddedness. Validating our hypotheses, we found that abusive supervision indirectly undermines job embeddedness through leader satisfaction, with the negative relationship being stronger for higher performers that have elevated WSSW evaluations. The fact that lower self worth employees reported a significantly weaker relationship between abusive supervision and leader satisfaction still supports SVT by indicating they were more tolerant of abusive supervision than higher self worth employees' (Swann, 1983; Wiesenfeld et al., 2007).

While Study 2 focused on a more proximal mediator and added an important control increasing our confidence in the findings, it still had its limitations. For example, common method variance (CMV) was present due to same source and temporal concerns (Podsakoff et al., 2003). In addition, although our findings are consistent with our integrative model of the active appraisal perspective and SVT, we have not explored whether dissatisfying self-verification crises spurn higher performers to voluntarily leave their organizations as a result of their reduced job embeddedness. Furthermore, even though the interaction patterns that arose in Studies 1 and 2 both support our proposed SVT perspectives, the magnitude of the effects differ across studies for those employees lower in performance. In particular, the effect of abuse on job satisfaction was substantially weakened to the point of statistical nonsignificance when job performance (and thus self worth evaluations) was lower in Study 1. In contrast, in Study 2 the relationship between abuse and satisfaction with the leader was weakened, but not eliminated, for those individuals lower in performance. While this is likely because satisfaction with the leader is more strongly correlated with abusive supervision, being that the attitudinal target is focused directly on the leader rather than one's general job, it would be beneficial to examine the relationship in another sample to ensure that such is indeed the case. Thus, we conducted Study 3 to alleviate these concerns by (a) utilizing time-separated variables, (b) adding voluntary turnover as an 
objective behavioral outcome of job embeddedness, and (c) exploring whether the interaction pattern displayed in Study 2 is replicated.

\section{5 | JOB EMBEDDEDNESS AND VOLUNTARY TURNOVER}

Given the theory and findings we present in Studies 1 and 2, as employees' performance increase, we expect them to be more likely to voluntarily quit their jobs due to the dissatisfaction and subsequently reduced job embeddedness that ensue upon encountering abusive supervision. Indeed, self-verification research in nonwork settings shows that one response to experiencing disaffirming interactions with prominent others is to sever the relationship (Cast \& Burke, 2002). In organizations, this occurs because individuals who perceive that their organization does not provide them what they desire (i.e., job embeddedness fit) become less professionally and personally tied to the organization (Mitchell et al., 2001). In addition, individuals that possess fewer positive links and more negative links, especially with prominent others at work, such as supervisors, are less apprehensive to break those links by leaving their organizations (Mitchell \& Lee, 2001). Finally, it is less of a sacrifice for employees that are dissatisfied with their supervisors to sever those ties by quitting their jobs. In summary, because higher performers who experience self-verification crises as a result of their leaders' abusive behaviors experience less job embeddedness fit, links, and sacrifice, we argue that they are more likely to voluntarily turnover. Preliminary evidence shows that employees are more likely to voluntarily turnover due to decreased embeddedness (e.g., Felps et al., 2009; Mitchell et al., 2001). Thus, we propose:

Hypothesis 4: Job performance indirectly moderates, via WSSW, the positive indirect effect of abusive supervision on voluntary turnover via satisfaction and then job embeddedness, such that this indirect effect will be more positive at higher (vs. lower) levels of performance.

\section{6 | STUDY 3 METHODS}

\section{1 | Sample and procedure}

Participants were full-time employees in a sales company located across the United States. Data were collected online in 2020 using four time-lagged surveys (IRB protocol from University of Nebraska- Lincoln. Title: "Employee Onboarding and Organizational Assimilation", IRB \#20200720485EX). At Time 1 (T1), we collected employee demographics, negative affect, and competence uncertainty. At Time 2 (T2), 1 week later, employees rated their supervisor's abusive supervision, their own job performance, and WSSW. At Time 3 (T3), 2 weeks later, they rated their satisfaction with their leader, and at Time 4 (T4), 2 weeks later, their job embeddedness. Approximately 4 months after T4, we assessed employees' voluntary turnover. As with Study 2 , we added an open-response question at the end of each survey, allowing employees to report issues they had during the data collection. Because the company went through some internal changes, we also received organizational records of employees' weekly changes in teams/supervisors.

We invited 802 employees to take the surveys. We received 689 complete responses ( $86 \%$ response rate) in T1. T2 responses were 588, T3 responses were 447, and T4 responses were 394. Of those, we excluded participants for noncompliance ${ }^{18}$ and/or various organizational changes that occurred during the study (e.g., altered job assignments or changed leader/teams, and admittance of dishonest responses) after T1. Similar to Studies 1 and 2, we used FIML to account for missing dependent variables in the analyses (Rubin \& Little, 2002), resulting in a final sample of 335 employees (49\% retention rate from T1). Employees were nested in 90 teams; thus, we had an average of 3.7 employees per supervisor that participated in the study. 
Employees were mostly male (69\%) and White (67\%). On average, they were 27 years old (SD $=6.2)$ and had an organization tenure of 25 months $(S D=38)$. About $87 \%$ had a college degree and $5 \%$ had a high-school diploma, with the rest being missing.

\subsection{1 | Measures}

Abusive Supervision, Job Performance, WSSWW, Leader Satisfaction, Job Embeddedness, Competence Uncertainty ${ }^{19}$, and Negative Affect ${ }^{20}$. These scales were measured as in Study 2 with the exception that for negative affect we used the 10-items scale (Watson \& Clark, 1994) instead of the shortened five-item scale.

Voluntary turnover. We confirmed from conversations with administrative personnel and access to personnel files that each employee indeed voluntarily withdrew from the organization. Those that voluntarily turned over were coded as 1 , and those remaining were coded as 0 .

\subsection{2 | Analyses}

Our analyses mirrored those of Studies 1 and 2 with the notable exception that our dataset had a nested structure (employees nested within leaders), and a categorical dependent variable. A variance component analysis indicated small amounts of between-unit variance (ranging from 1\% to 15\%); nevertheless, this nonindependence needed to be accounted for, and thus we utilized a multilevel model. In addition, because voluntary turnover is categorical, a path model with Monte Carlo integration was necessary to conduct this analysis in Mplus 8.

\section{2 | Results}

As in Studies 1 and 2, we conducted a series of CFAs (using a multilevel approach) in Mplus 8. We first examined the hypothesized 7-factor model (i.e., abusive supervision, self worth, job performance, leader satisfaction, job embeddedness, negative affect, and competence uncertainty). The model largely displayed adequate fit $\left(\chi^{2}(681)=1616.30\right.$, $p=.00 ; \mathrm{CFI}=.89 ; \mathrm{TLI}=.88 ; \mathrm{SRMR}_{\text {within }}=.06 ; \mathrm{RMSEA}=.06 ; \mathrm{Hu} \&$ Bentler, 1999). In nested models, however, cluster size as well as average cluster size can have implications for model estimation (Koch et al., 2015). As our sample size was 335 employees nested within 90 leaders, we adopted the same parceling approach as in Study 2 to ensure that the convergence of the model was not a problem (thus, we adopted the same two parceling approaches used in Study 2 as supplemental tests of our model [Williams et al., 2020]). CFA (using a multilevel approach) results of the seven-factor model using the balancing approach (Little et al., 2013) showed good model fit $\chi^{2}{ }_{(131)}=249.93, p=.00 ; \mathrm{CFI}=.97$; $\left.\mathrm{TLI}=.96 ; \mathrm{SRMR}_{\text {within }}=.04 ; \mathrm{RMSEA}=.05\right)$. Alternative models uniting performance with self worth, and leader satisfaction with embeddedness showed worse fit $\left(\Delta \chi^{2}=311.09, \Delta \mathrm{df}=6, p=.00 ; \Delta \chi^{2}=387.17, \Delta \mathrm{df}=6, p=.00\right.$, respectively), supporting the hypothesized factor structure. We also reran our parcels using random parcel assignment (e.g., Koopman et al., 2019). The model showed adequate fit $\left(\chi^{2}{ }_{(131)}=275.34, p=.00 ; \mathrm{CFI}=.97 ; \mathrm{TLI}=.96 ; \mathrm{SRMR}_{\text {within }}=.04\right.$; $\mathrm{RMSEA}=.06, \mathrm{Cl}_{95 \%}=.08, .11$ ). These results validated the goodness of fit of the data to the proposed measurement model $^{21}$.

Table 5 shows means, standard deviations, alpha reliabilities, and correlations among the variables included in this study. Table 6 shows the results of the path model testing our hypotheses. Job performance had a significant positive effect on self worth $(\gamma=.42, p=.00)$, supporting Hypothesis 1 . Next, we tested the moderating role of self worth on the relationship between abusive supervision and leader satisfaction, controlling for negative affect, competence uncertainty, job performance and the interaction of abusive supervision and job performance. Results showed that self worth is a significant moderator $(\gamma=-.31, p=.01$; see Figure 4$)$, such that the negative effects of abusive 
TAB LE 5 Descriptive statistics and correlations (Study 3)

\begin{tabular}{|c|c|c|c|c|c|c|c|c|c|c|}
\hline & & $M$ & $S D$ & 1 & 2 & 3 & 4 & 5 & 6 & 7 \\
\hline 1. & Negative Affect (T1) & 1.55 & 0.54 & (.87) & & & & & & \\
\hline 2. & Competence Uncertainty (T1) & 1.98 & 0.90 & .33 & (.88) & & & & & \\
\hline 3. & Abusive Supervision (T2) & 1.41 & 0.69 & .26 & 22 & (.96) & & & & \\
\hline 4. & Job Performance (T2) & 4.54 & 0.48 & -.19 & -.30 & -.23 & (.88) & & & \\
\hline 5. & Self-Worth (T2) & 3.99 & 0.70 & -.41 & -.41 & -.29 & .40 & (.90) & & \\
\hline 6. & Leader Satisfaction (T3) & 4.07 & 0.95 & -.25 & -.12 & -.53 & .18 & .27 & $(.97)$ & \\
\hline 7. & Job Embeddedness (T4) & 3.10 & 1.04 & -.28 & -.08 & -.26 & .16 & .39 & .52 & (.97) \\
\hline 8. & Voluntary Turnover (T5) & .09 & .28 & .08 & .03 & .06 & .02 & -.23 & -.03 & -.21 \\
\hline
\end{tabular}

Note. $N=335$. Correlations greater than or equal to $|.10|$ are significant at $p<.10$; those greater than or equal to $|.11|$ are significant at $p<.05$; those greater than or equal to $|.15|$ are significant at $p<.01$. Voluntary turnover: $1=$ voluntary turnover, $0=$ all others. Alpha reliabilities of the scales are in parentheses on the diagonal.

supervision were more strongly negative for higher self worth employees relative to lower self worth employees. Combining these two effects tests for the indirect moderating effect of job performance through self worth on the relationship between abusive supervision and leader satisfaction; this indirect moderating effect was significant and in the expected direction ( $\left.I E=-.13, C_{95 \%}=-.25,-.04\right)$. Specifically, the slope of abusive supervision for higher performers (through self worth) was significantly negative $(\gamma=-.85, p=.00)$, while being weaker for lower (-1SD) performers $(\gamma=-.67, p=.00)$, supporting Hypothesis 2 . Similar to Study 2 , although the slopes differed significantly (diff $=-.18$, $\mathrm{Cl}_{95 \%}=-.35,-.06$ ), both indirect effects remained negative and significant across all observed moderator levels, likely due to the main effect of abusive supervision in these data being more strongly related to the more proximal mediator of leader satisfaction, relative to job satisfaction.

We then tested the effect of leader satisfaction on job embeddedness. The path model shows that leader satisfaction was positively associated with job embeddedness $(\gamma=.54, p=.00)$. The conditional indirect effect of abuse on embeddedness via satisfaction for higher performers was significantly negative ( $I E=-.46, C_{95 \%}=-.65,-.31$ ), while the same effect was weaker for lower performers (IE $\left.=-.36, \mathrm{Cl}_{95 \%}=-.51,-.24\right)$. A supplemental analysis displayed that the conditional indirect effects were significantly different from each other (diff $=-.10, \mathrm{Cl}_{95 \%}=-.21,-.03$ ), supporting Hypothesis 3.

Finally, we tested the effect of job embeddedness on voluntary turnover. Results show a significant negative relationship $(\gamma=-.74$, odds ratio $[O R]=.48, p=.004)$, indicating that one unit increase in job embeddedness was associated with employees being only $48 \%$ as likely to turnover relative to the baseline, all things being equal. The conditional indirect effect of abuse on voluntary turnover for higher performers was significantly positive (IE $\left.=.34, \mathrm{Cl}_{95 \%}=.02, .75\right)$, while the same effect was weaker for lower performers (IE $=.27, \mathrm{Cl}_{95 \%}=.02, .60$ ). These two conditional indirect effects were statistically different from each other (diff $=.07, \mathrm{Cl}_{95 \%}=.01, .22$ ), which supports Hypothesis 4.

\section{7 | GENERAL DISCUSSION}

We conducted three field studies to examine how job performance differentially impacts the extent to which abusive supervision influences employees' job embeddedness and decisions to turnover. We found that these effects are (a) conditional on employees' self-views at work as a result of their job performance, and (b) operate through employees' satisfaction. More specifically, across three studies, we found support for SVT in that the deleterious effects of abuse onto employees' decisions to quit through satisfaction and job embeddedness were strengthened as performance (and 


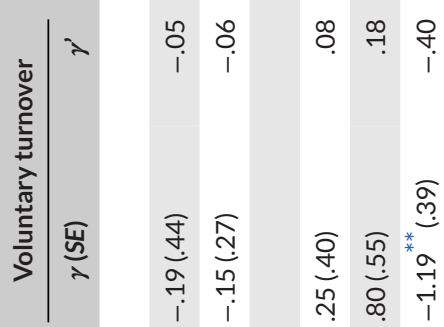

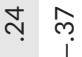

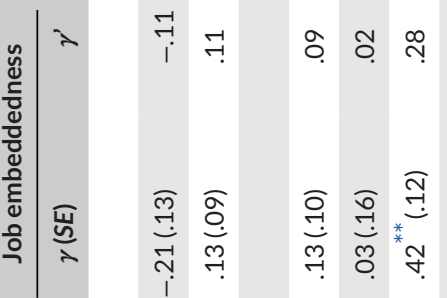

$\stackrel{\infty}{+}$

先?

กั

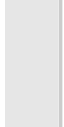

ป

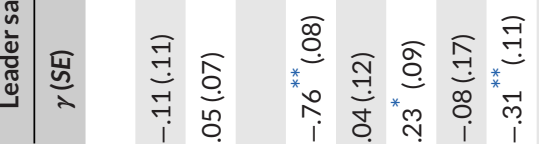

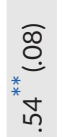

ले

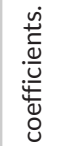

ले.

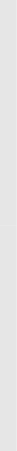



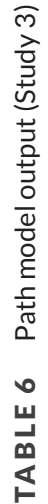

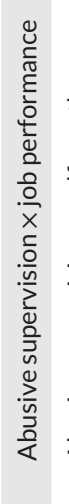

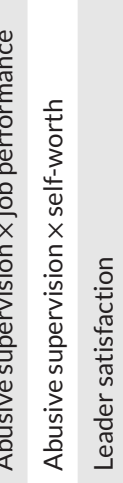

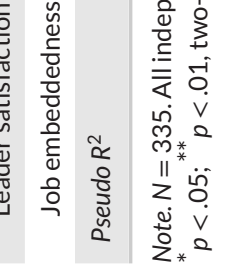


FIGURE 4 Interaction of abusive supervision and self-worth on leader satisfaction (Study 3)

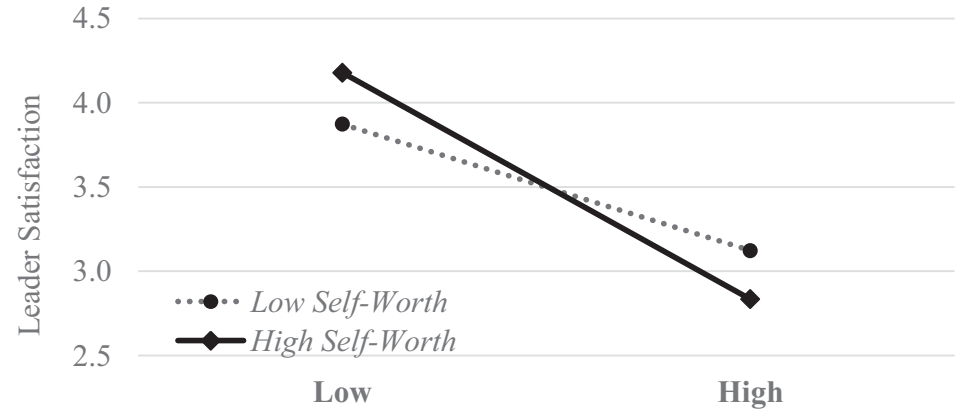

Abusive Supervision

thus self worth evaluations) increased, while these deleterious indirect effects were weakened as performance (and thus self worth evaluations) decreased. Importantly, we show that self-views are a mediator of this moderating effect, with job performance indirectly moderating (via its impact on WSSW) the effects of abusive supervision on satisfaction, job embeddedness, and subsequent voluntary turnover. Finally, we found that abusive supervision was associated with both general attitudes (job satisfaction) and targeted attitudes (satisfaction with the leader). Interestingly, we discovered that as performance and subsequent self worth decreased, the negative effects of abusive supervision on job satisfaction weakened to statistical nonsignificance (Study 1), whereas the same effects on leader satisfaction were simply weakened (Studies 2 and 3). Fishbein's (1966) "principle of compatibility" may help to explain these interesting findings. According to the principal of compatibility argument, targeted attitudes are more strongly predicted by and predictive of behavioral antecedents and outcomes that share a similar target. Because job satisfaction is a more general evaluation of the job that encompasses many facets of satisfaction (e.g., coworker, pay, task, promotion, and supervisor; Griffeth et al., 2000), abusive supervision is likely to account for a smaller amount of its variance. However, leader satisfaction is an attitude targeted at the leader. Thus, the target alignment that exists between abusive supervision and leader satisfaction may be why we find stronger direct effects between the two variables (see Fisher, 1980).

\section{1 | Theoretical implications}

Our first set of implications relate to the competing conclusions derived from SEnT (particularly its compensatory perspective) and SVT (see De Cremer, 2003; Jones, 1973; Leary \& Baumeister, 2000; Swann, 1983). The theories diverge with regard to whether those with higher or lower self worth react more negatively to negative (generally speaking) leader interactions (e.g., abusive supervision). The latter suggests that individuals desire interactions that affirm their self worth. Thus, lower performers should at least tolerate and could even be satisfied with abusive supervision as it, to a degree, affirms their lower self worth perceptions. However, as performance improves, employees should progressively be more dissatisfied with leader abuse as the abuse increasingly contradicts their self worth perceptions. In contrast, the former theory argues that abusive interactions would be highly dissatisfying for all employees, especially those with decreasing performance because the abuse does not compensate for their lower self worth perceptions. Interestingly, across three studies, we repeatedly found that the higher employees' performance and their subsequent work-specific self-views, the more strongly negative their attitudinal responses were to supervisors' abuse. Inversely, the lower employees' performance and their ensuing work-specific SW, the more tolerant they were of supervisors' abuse, displayed by weakened relationships between abuse and satisfaction.

Subsequently, our findings are more in line with SVT (relative to SEnT in general and its compensatory form), at least with regard to aversive experiences, such as abusive supervision at work. This is theoretically important because 
SEnT's emphasis that individuals only seek positive interactions has led researchers to assert "that the desire for selfenhancement overrides the desire for accurate self-knowledge" (Kwang \& Swann, 2010, p. 264), which is a stronger conclusion than is warranted by previous research and can lead to erroneous implications. Our study casts doubt on that perspective by arguing, and providing empirical evidence, for the relevance of self-verification perspectives (specifically about abusive supervision). That is, we show that those with lower self worth perceptions are more tolerant of abusive supervision because it is self-verifying, which likely makes abusive supervision less visible amongst organizational leaders. This can be particularly harmful if people develop inappropriately low self worth perceptions at work (i.e., self worth views that exaggerate or misrepresent their limitations; Talaifar \& Swann, 2020).

Furthermore, our study argues for a more nuanced view of SVT. Although we find evidence of the benefits of consistency between how employees see themselves and how others treat them when it comes to higher self worth employees, for employees lower in self worth, consistency does not have a corresponding positive effect - rather, it merely minimizes the impact of abusive supervision. These findings join other related self-verification research in showing that SVT effects are not always symmetrical (Cable \& Kay, 2012; Wiesenfeld et al., 2007), creating the impetus for more carefully considered predictions about the effects of positive (or negative) experiences on employees holding positive (or negative) self-views. Ultimately, our research can help understand the circumstances in which people with unique self-views might differentially react or, as in our case, circumstances in which a given effect is only found for a particular group of people and merely weakened for another group of people.

There are at least three reasons for why, across three studies, we did not find that lower self worth individuals experience satisfaction when they encounter abusive supervision, especially because past studies indicate that lower selfesteem individuals opt for negative interactions (Giesler et al., 1996). First, SVT only predicts that lower self worth individuals are less likely to be dissatisfied with abusive supervision than higher self worth individuals; the theory refrains from predicting the magnitude of the difference (Swann \& Buhrmeister, 2012). This is because a key assumption of SVT is that "self-verification strivings are stronger insofar as the [interpersonal interaction] matches people's self-views (Bosson \& Swann et al., 1999)" (Wiesenfeld et al., 2007, p. 1237). However, theory is unclear as to how this might relate to openly hostile behaviors (e.g., abusive supervision). Therefore, while employees' negative self-views may lead them to expect and thus tolerate negative leader treatment, those self-views may not be so negative as to conclude that it is appropriate for a leader to openly yell at, demean, or humiliate (i.e., abuse) them. As a result, even though lower self worth individuals may be more tolerant of negative leader treatment than higher self worth individuals, if the leaders' behaviors are sufficiently egregious, they could still disaffirm, to an extent, their negative self-views (Wiesenfeld et al., 2007), which is one potential reason why across three studies we do not find abusive supervision to result in greater satisfaction for those with lower self worth.

Second, prior work has not examined abusive supervision through a self-verification lens, thus people may not respond to abusive supervision in the same way as other self-evaluative information, because it matters for reasons other than self-evaluative implications. For example, abuse has been linked to encouraging greater performance (Liu et al., 2012) or some may see it as a type of prototypical leadership (Epitropaki \& Martin, 2004; Tu et al., 2018), both of which work against discovering a symmetrical effect among lower SW individuals, by reducing the match between one's SW and the negative interactions (Bosson \& Swann, 1999).

Finally, the effects may not have turned positive for lower self worth individuals due to constrained variance in job performance and self worth, being that organizations are likely to terminate their poorer performing employees (Stumpf \& Dawley, 1981) and evidence shows that approximately $70 \%$ of people have positive self-views (Diener \& Diener, 1995). To that end, SVT studies where researchers have found symmetrical results often take place in laboratory studies in which the samples are constrained to those in the lowest and highest $20 \%$ percentile of self worth (see De La Ronde \& Swann, 1998; Hixon \& Swann, 1993; Swann et al., 1992).

Beyond these distinctions, we also contribute to active appraisal perspectives and SVT, by integrating them to show that individuals' own performance at work is a central predictor of how they see themselves at work (Leary \& Baumeister, 2000; Leary \& Downs, 1995). Past work has demonstrated a disconnect between universal self-views and performance (Judge \& Bono, 2001); however, across three unique studies, we demonstrate that job performance 
perceptions are related to work-specific evaluations of self worth (thus generalizing previous within-domain work to the workplace; see Marsh et al., 1999, 2006), which answers a recent call for research to uncover how to improve self worth perceptions (Talaifar \& Swann, 2020). This opens up new avenues for research. That is, by integrating these two theories, SVT researchers can greatly increase their understanding of the antecedents of self-views (with the clearest implications of our work being the need to analyze specific facets that match within the studied domain), while research on workplace performance can benefit from a new framework to investigate the impact of workplace events on individuals of varied accomplishments.

More specifically, this contribution enhances SVT by demonstrating the role of employees' own behavior on their self views - as such, it allows for theorizing on positive (or negative) effects based on one's actions rather than dispositions or external factors (Vogel \& Mitchell, 2017), thus broadening the scope of SVT. On a related note, it allows for an interface with multiple dynamic frameworks of workplace functioning (such as episodic views of performance; see Beal et al., 2005) that can account for within-person effects over time, in turn, extending the bounds of the theoretical framework. Thus, we provide an initial platform for exploring additional behaviors (e.g., citizenship behaviors, proactivity, or creativity) that may influence self-views and therefore impact how individuals react to their experiences at work.

More broadly, our focus on attitudes within the SVT framework can also provide insights to the broader literature on negative behaviors at work. Our theoretical reasoning indicates that not only are attitudes a core mechanism in determining individual responses to abusive supervision, but they can have differential effects only previously identified in the literature within a cross-cultural context (Kernan et al., 2011). That is, we show that abusive supervision does not always have a negative effect on workplace attitudes (see Mackey et al., 2017). While a consistent effect would be more in line with SEnT (especially the hedonic view), we show that a SVT perspective is more applicable and provides a nuanced and important boundary condition of this effect. That is, our theoretical model shifts the consensus by clarifying when abuse may be more versus less dissatisfying, which enhances our theoretical understanding and hopefully spurs future research on how SVT experiences impact other indirect outcomes of abusive supervision (e.g., employee aggression or ostracism toward the leader).

Finally, we contribute to the literature on higher performers (e.g., star employees; Call et al., 2015; Messersmith \& Guthrie, 2010) by revealing what keeps them from staying in their organizations. Specifically, our integrative model of active appraisal perspectives and SVT underscores the dangers of exposing higher performers to toxic leadership (e.g., abuse). We consistently found that as performance increases, employees report greater dissatisfaction to these experiences. Due to how important higher performers are to companies, this can have severe implications for the functioning and success of a company (Trevor et al., 2007; Wright \& McMahan, 1992). For example, higher performers are more visible in organizations and are often viewed as role models (Groysberg \& Lee, 2010), which enhances the likelihood of negative contagion effects (regarding their attitudes, cognitions, and behaviors). Thus, frameworks that investigate organizational success based on higher performers would be benefitted by integrating our arguments to demonstrate when aversive leadership might be especially hazardous.

\section{2 | Practical implications}

These results carry a number of practical and managerial implications. The most obvious is that the negative effects of abusive supervision are strongest amongst those displaying higher performance levels. Specifically, allowing higher performers to experience abusive supervision undermines their connection to their jobs and raises their likelihood of quitting, which are highly damaging to organizational performance (Kwon \& Rupp, 2013; Nyberg, 2010). Moreover, because higher performers are more visible and central to organizational functioning, others view them as exemplars, thus enabling their attitudes, intentions, and behaviors - whether good or bad - to be replicated across the organization (Aguinis \& O'Boyle, 2014; Groysberg \& Lee, 2010; Oldroyd \& Morris, 2012). As a result, abusing higher performers can be doubly harmful for organizations because their reduced satisfaction, embeddedness, and increased turnover 
may contagiously spread amongst others, creating a toxic organizational environment. Thus, it behooves leaders to be vigilant of abusive supervision, especially amongst higher performers.

Another implication of our findings relates to lower performers. Specifically, we find that lower performers are more tolerant of abusive supervision. This can have a subtle subduing effect, making abusive supervision less evident to others. As such, abusive supervisors might be enabled to mistreat lower performers as the harmful consequences of abuse are at least weakened, making them less likely to be detected. It is, thus, important for organizational leaders to be aware of this possibility and monitor for abuse directed at all employees. This may be done by training leaders and employees alike about what abusive supervision entails, encouraging employees to speak up when abused, and conducting exit interviews with all employees.

Finally, we show that leaders play a critical role in the development of job embeddedness and subsequent employee turnover decisions, especially amongst their most valuable human assets (i.e., higher performers). Call et al. (2015) advocate that for higher performers, leaders should proactively manage the creation of job embeddedness ties inside and outside of their organizations as a means of retaining these important human assets in the organization. We expand upon that by advocating that leaders themselves need to also account for their own leadership behaviors toward their employees when it comes to managing job embeddedness amongst their employees. Specifically, our research shows that negative leader behaviors toward employees, especially those performing highly, are dramatically detrimental to job embeddedness. Thus, above and beyond planning appealing social activities inside and outside of the organization to develop job embeddedness linkages, leaders need to proactively ensure that their own behaviors are not undermining the very job embeddedness that they and their organizations are actively seeking to develop amongst their employees, especially higher-performing employees.

\section{3 | Limitations and future directions}

This study has a number of limitations that should be acknowledged. The first is that although it is a strength of our research that across three time-lagged samples from multiple contexts we consistently found support for our model, the first two studies each only utilized a single time lag, with satisfaction and job embeddedness being measured concurrently, which introduces potential CMV concerns (Podsakoff et al., 2003). However, the magnitudes of the effects in the studies most vulnerable to such concerns (Studies 1 and 2) were very similar to those in the study that temporally separated those variables and had an objective dependent variable (Study 3) and, also, generally in line with existing research. In addition, the studies had relatively low response rates, which is not unusual in prior abusive supervision research (e.g., Thau \& Mitchell, 2010). However, these concerns are partly ameliorated by two factors. First, no consistent relationship arose between study variables and data missingness (with only one such significant relationship being found, which did not replicate across other studies), implying that systematic bias in responses is unlikely. Second, the results were consistent across studies, which suggests that response rates did not influence the results. Moreover, the relationships in our model (i.e., job/leader satisfaction on the self-rated outcomes) have magnitudes and signs in line with past research among related variables (Mitchell et al., 2001; Ogunfowora, 2013; Swider et al., 2011), further increasing our confidence in the results. Regardless, additional replication of our model using extended time lags and higher response rates would be beneficial.

Furthermore, across all studies, we incorporated important control variables that could affect our predictions. However, a limitation in Study 1 was that negative affect had a low reliability score $(\alpha=.58)$. We addressed this limitation in Study 3 with a more reliable negative affect scale that entailed more items. In addition, across all studies, we tested the hypothesized model with and without the control variables and the results were unaffected.

Another limitation of this paper is our incomplete understanding of why (and when) higher performers might be subject to abusive supervision behaviors in the first place. Although past research has explored some possibilities (Courtright et al., 2016; Khan et al., 2018; Tepper et al., 2011; Wang et al., 2015), scope issues prohibited us from further pursuing this line of research. To the extent that we are unaware of potential reasons for this behavior, 
possibilities to draw erroneous conclusions remain. For instance, other perspectives indicate that higher performers are more likely to be abused due to threatening the organization's hierarchy (see Khan et al., 2018) and that abuse is a function of leader states (i.e., ego depletion) that can apply to any employee, regardless of performance (Courtright et al., 2016). Therefore, it would be helpful for future research to explore whether higher performers have differential self-verification experiences if they perceive their leader's abuse as strategically intentional versus accidental, especially given (as we show) abusive supervision increases the likelihood of higher performers leaving their organizations.

Another factor that remains to be examined is whether performance via self-views is unique as a boundary condition of the effects of abusive supervision on satisfaction, or whether performance and ensuing self-views could also indirectly interact with other negative or even positive organizational stimuli to impact employees. As we only examined one negative factor in this study, we provide initial evidence of this possibility. However, future research on job performance that includes other interactional factors such as trust defiance, in addition to abusive supervision, would help to further solidify the underlying mechanisms in a way that we only begin to explore. In addition, future research would benefit by investigating whether positive forms of leadership (e.g., Chiaburu et al., 2014) might have interactive effects in the opposite direction with job performance (through self worth evaluations) on employee satisfaction and subsequent behaviors. Alternatively, the potential for differential effects of behaviors (positive or negative) of other prominent actors at work (i.e., a high-status coworker) on higher or lower performers could be another beneficial line of inquiry.

Similarly, we only investigated the indirect moderating effects of job performance (through self worth). A comparison approach contrasting these indirectly moderating effects of other types of performance (e.g., citizenship behaviors) with abusive supervision would help clarify whether task- and non-task-related performance variables, for example, operate similarly. Specifically, an investigation of the effects of other performance types and parallel negative behaviors (e.g., leader ostracism or trust defiance) would reinforce some of our arguments and extend our ideas to a broader class of psychological phenomena. In addition, while we find that self-reported job performance impacts WSSW, it would be fruitful to explore whether other- or objectively reported (e.g., sales) performance display similar effects on self worth evaluations and subsequent self-verification experiences.

Finally, we focused on a single class of mediating processes - workplace attitudes in the form of job satisfaction and satisfaction with the leader. Undoubtedly other cognitive and affective processes might play a role, and future research could investigate the relative importance of these. In addition, a closer test of the mechanisms linking abusive supervision to work attitudes would clarify whether these effects operate through cognitive beliefs on why they are aversive (i.e., actual violations of self-verification expectations) or through more immediate affective processes (i.e., anger or general negative affect).

\section{CONCLUSION}

Higher performers are extremely important to the success of organizations, making it important to understand the factors that impact whether they choose to leave their organizations (Nyberg, 2010). To that end, we show that employees' work-specific self-views, which are impacted by their job performance, can influence how strongly they respond to abusive supervision. Our findings are particularly important because they provide additional insights about the costs associated with abusive supervision, by showing that organizations' most valuable assets (i.e., higher performers) are much less likely to be organizationally embedded and more likely to quit when they are subject to abusive supervision. Indeed, across three field studies, we find that job and leader satisfaction of higher performers is undermined more severely than lower performers, which thus reduces higher performers' job embeddedness and subsequent likelihood of voluntarily leaving their organizations. These findings are especially impactful given higher performers' visibility inside their organizations and their abilities to impact other employees' attitudes and behaviors (Aguinis \& O'Boyle, 2014; Groysberg \& Lee, 2010) and the detrimental impact their turnover has on organizational performance (Kwon \& Rupp, 2013). 


\section{ORCID}

Troy A. Smith (1) https://orcid.org/0000-0002-8173-8511

Artemis Boulamatsi (i) https://orcid.org/0000-0001-9854-1750

Nikolaos Dimotakis (iD https://orcid.org/0000-0001-8448-1072

Christopher S. Reina (1) https://orcid.org/0000-0002-7876-9771

\section{ENDNOTES}

1 Throughout the manuscript, at times, we refer to "higher performer" and "lower performer" in a categorical manner for ease in explaining the opposing perspectives of SVT, which is common in SVT research (see Talaifar et al., in press; Wiesenfeld et al., 2007). Nevertheless, in this study, performance is a continuous variable, with those exhibiting increasing (decreasing) performance being reflective of "higher (lower) performers."

${ }^{2}$ While past studies show that abusive supervision can be targeted at lower performers (Tepper et al., 2011), it can also be less targeted and more impulsive (Courtright et al., 2016), making higher performers potential recipients of it. Indeed, Khan et al. (2018) show that leaders abuse higher performers when they are viewed as threatening.

3 We focus on self worth rather than self-esteem because Wiesenfeld et al. (2007) indicate that in the workplace, self worth is "the component of self-esteem that SVT suggests would be most sensitive to evaluative information" (p. 1244).

4 Although Judge and Bono (2001) found that the relationship between global self-esteem and job performance to be variable, domain-specific performance has been shown to be more predictive of corresponding domain-specific self-esteem (Marsh et al., 1999) relative to global self-esteem. Thus, rather than proposing that job performance impacts global selfesteem, we follow the suggestion of Marsh et al. (2006) and focus on how job performance impacts WSSW (i.e., one's feeling about the self at work). This is in line with Fishbein's (1966) argument that targeted evaluations and behaviors (i.e., job performance, WSSW, or job satisfaction) are likely to be more strongly predicted by and predictive of other similarly targeted evaluations and behaviors compared to general or global evaluations (i.e., global self worth or life satisfaction).

5 First, we excluded evidently noncompliant responses (i.e., surveys left open for more than 24 hours). We then examined the median response time (15 $\mathrm{min}$ ), and selected cases within $10 \mathrm{~min}$ (i.e., two-thirds of the median) of that (i.e., 25 min; note that any responses below 5 min were already excluded due to missing data so idleness was the only remaining criteria). Removing this selection did not affect the magnitude or significance of the path model coefficients.

6 We focus on WSSW rather than the related organization-based self-esteem (OBSE) because the former depends on how individuals feel about themselves, whereas OBSE includes how individuals view that other people treat them (example OBSE items are: "Around here I am taken seriously" and "Around here I am trusted"). In addition, the former is more statelike thus allowing it to be driven by one's own actions and behaviors, whereas OBSE "is less malleable," especially as tenure increases because greater tenure makes OBSE "a less changeable inner level self-concept" (Pierce \& Gardner, 2004, p. 593; Pierce et al., 1989). In turn, WSSW is more focused and thus more closely linked to domain-specific actions as opposed to being a more stable and holistic evaluation (Fishbein, 1966).

7 Following Becker's (2005) recommendations, we ran the model with no control variables and the study conclusions remained unchanged.

8 Detailed results for this study (as well Studies 2 and 3) can be made available by the corresponding author.

9 Details of the alternative models for this study (as well as Studies 2 and 3) can be made available by contacting the corresponding author.

10 Due to ceiling effects, "higher" refers to only .4 SDs above the mean, corresponding to a value of 4.95 in a 5-point scale, instead of the typical 1 SD above the mean. For lower job performance, "lower" refers to the typical level of 1 SD below the mean.

11 These data were part of a larger data collection. Part of that larger data collection was also utilized to test a separate theoretical model (see Study 2 of Rosen et al., 2020). However, there were no overlapping variables between that study and this study.

12 Specifically, one employee indicated that some questions were not relevant to their work, so they generically marked " 3 " or " 5 " across multiple scales, another single employee indicated that the organizational records assigned them to the wrong supervisor, one employee whose leader reported that they were no longer involved in actively supervising any subordinates as a whole, and 12 employees indicated their supervisor changed during the study.

13 Similar to Study 1, we ran the model with no control variables and the study conclusions remained unchanged.

14 In supplemental analysis, we also controlled for the abusive supervision $\times$ competence uncertainty interaction. Results of our path model showed that the interaction term was not significant and our hypothesized model remained unchanged.

15 To ensure invariance of the measurement model across the two groups of employees, we tested invariance of the factor structure (configural invariance). The seven-factor model had an adequate fit with the data for full- and part-time employees $\left(\chi^{2}{ }_{(262)}=476.61, p=.00 ; \mathrm{CFI}=.92 ; \mathrm{TLI}=.90 ; \mathrm{SRMR}=.07 ; \mathrm{RMSEA}=.10 ; \mathrm{Hu} \&\right.$ Bentler, 1999). We also tested model invariance. The fit of the constrained model (path coefficients set to be the same across both groups of employees) was 
not statistically different from that of the unconstrained model (path coefficients allowed to vary across both groups of employees), $\Delta \chi^{2}(16)=23.31, p=.11$, supporting the same path model for both full- and part-time employees.

16 The ratio of items to sample size is below 5 for Study 2, whereas for Study 1 it is 6.7 and for Study 3 it is 8.6 . Therefore, Study 2 justifies exploring alternative modeling strategies.

17 We also estimated this model using the parcels utilized for the factor analyses. Statistical significance of results and our conclusions remained substantively the same.

18 Similar to Study 2, we included responses that had an average duration across all waves between 5 and 25 min. In addition, we examined whether employees had any interaction with their supervisor during the survey. We did not find any case that would affect the quality of responses. Finally, we excluded one participant that revealed in the open-ended question that they did not trust the survey and thus was not honest in their responses.

19 Similar to Study 2 in supplemental analysis, we also controlled for the abusive supervision $\times$ competence uncertainty interaction. Results of our path model showed that the interaction term was not significant, and our hypothesized model remained unchanged.

20 Similar to Studies 1 and 2, we ran the model with no control variables, and the study conclusions remained unchanged.

21 Similar to Study 2, we also estimated this model using the parcels utilized for the factor analyses. We found that all conclusions were substantively the same among the parcel models versus the item-based model.

\section{ACKNOWLEDGMENTS}

We express our appreciation to Dr. Marie S. Mitchell and two Personnel Psychology anonymous reviewers for their highly constructive feedback that enabled us to improve our manuscript.

\section{DATA AVAILABILITY STATEMENT}

The data that support the findings of this study are available from the corresponding author upon reasonable request.

\section{REFERENCES}

Aguinis, H., \& O’Boyle Jr, E. (2014). Star performers in twenty-first century organizations. Personnel Psychology, 67, 313-350. https://doi.org/10.1111/peps.12054

Allen, D. G., Bryant, P. C., \& Vardaman, J. M. (2010). Retaining talent: Replacing misconceptions with evidence-based strategies. Academy of Management Perspectives, 24, 48-64. https://doi.org/10.5465/amp.24.2.48

Allport, G. W. (1937). Personality: A psychological interpretation. New York: Holt.

Ayduk, O., Gyurak, A., Akinola, M., \& Mendes, W. B. (2011). Self-verification processes revealed in implicit and behavioral responses to feedback. UC Berkeley.

Bandura, A. (1990). Perceived self-efficacy in the exercise of personal agency. Journal of Applied Sport Psychology, 2, $128-163$. https://doi.org/10.1080/10413209008406426

Barkow, J. H. (1980). Prestige and self-esteem: A biosocial interpretation. In D. R. Omark, F. Strayer, \& D. G. Freedman (Eds.), Dominance relations: An ethological view of human conflict and social interaction (pp. 319-332). Garland STPM.

Barney, J. (1991). Firm resources and sustained competitive advantage. Journal of Management, 17, 99-120. https://doi.org/ 10.1177/014920639101700108

Barrick, M. R., Thurgood, G. R., Smith, T. A., \& Courtright, S. H. (2015). Collective organizational engagement: Linking motivational antecedents, strategic implementation, and firm performance. Academy of Management Journal, 58, $111-135$. https://doi.org/10.5465/amj.2013.0227

Beal, D. J., Weiss, H. M., Barros, E., \& MacDermid, S. M. (2005). An episodic process model of affective influences on performance. Journal of Applied Psychology, 90, 1054-1068. https://doi.org/10.1037/0021-9010.90.6.1054

Becker, T. E. (2005). Potential problems in the statistical control of variables in organizational research: A qualitative analysis with recommendations. Organizational Research Methods, 8, 274-289. https://doi.org/10.1177/1094428105278021

Becker, B. E., \& Huselid, M. A. (2006). Strategic human resources management: Where do we go from here?. Journal of Management, 32, 898-925. https://doi.org/10.1177/0149206306293668

Bosson, J. K., \& Swann Jr W. B.(1999). Self-liking, self-competence, and the quest for self-verification. Personality and Social Psychology Bulletin, 25, 1230-1241. https://doi.org/10.1177/0146167299258005

Brockner, J. (1988). Self-esteem at work: Research, theory, and practice. Lexington Books/DC Heath and Com.

Burke, P. J., \& Stets, J. E. (1999). Trust and commitment through self-verification. Social Psychology Quarterly, 347-366. https://doi.org/10.2307/2695833

Cable, D. M., \& Kay, V. S. (2012). Striving for self-verification during organizational entry. Academy of Management Journal, 55, 360-380. https://doi.org/10.5465/amj.2010.0397 
Call, M. L., Nyberg, A. J., \& Thatcher, S. (2015). Stargazing: An integrative conceptual review, theoretical reconciliation, and extension for star employee research. Journal of Applied Psychology, 100, 623-640. https://doi.org/10.1037/a0039100

Campbell, E. M., Liao, H., Chuang, A., Zhou, J., \& Dong, Y. (2017). Hot shots and cool reception? An expanded view of social consequences for high performers. Journal of Applied Psychology, 102, 845-866. https://doi.org/10.1037/apl0000183

Cast, A. D., \& Burke, P. J. (2002). A theory of self-esteem. Social Forces, 80, 1041-1068. https://doi.org/10.1353/sof.2002.0003

Chen, G., Smith, T. A., Kirkman, B. L., Zhang, P., Lemoine, G. J., \& Farh, J. L. (2019). Multiple team membership and empowerment spillover effects: Can empowerment processes cross team boundaries?. Journal of Applied Psychology, 104, 321-340. https://doi.org/10.1037/apl0000336

Chiaburu, D. S., Smith, T. A., Wang, J., \& Zimmerman, R. D. (2014). Relative importance of leader influences for subordinates' proactive behaviors, prosocial behaviors, and task performance. Journal of Personnel Psychology, 13, 70-86. https://doi.org/ 10.1027/1866-5888/a000105

Cole, J. R., \& Cole, S. (1973). Social stratification in science. University of Chicago Press.

Courtright, S. H., Gardner, R. G., Smith, T. A., McCormick, B. W., \& Colbert, A. E. (2016). My family made me do it: A crossdomain, self-regulatory perspective on antecedents to abusive supervision. Academy of Management Journal, 59, 16301652. https://doi.org/10.5465/amj.2013.1009

Crossley, C. D., Bennett, R. J., Jex, S. M., \& Burnfield, J. L. (2007). Development of a global measure of job embeddedness and integration into a traditional model of voluntary turnover. Journal of Applied Psychology, 92, 1031-1042. https://doi.org/10. 1037/0021-9010.92.4.1031

De Cremer, D. (2003). Why inconsistent leadership is regarded as procedurally unfair: The importance of social self-esteem concerns. European Journal of Social Psychology, 33, 535-550. https://doi.org/10.1002/ejsp.162

De La Ronde, C., \& Swann Jr, W. B. (1998). Partner verification: Restoring shattered images of our intimates. Journal of Personality and Social Psychology, 75, 374-382. https://doi.org/10.1037/0022-3514.75.2.374.

Deloitte Human Capital. (2008). The chemistry of talent. Straight talk book no. 10. Deloitte Development, LLC.

Diener, E., \& Diener, M. (1995). Cross-cultural correlates of life satisfaction and self-esteem. Journal of Personality and Social Psychology, 68, 653-663.

Edwards, J. R., \& Lambert, L. S. (2007). Methods for integrating moderation and mediation: A general analytical framework using moderated path analysis. Psychological Methods, 12,1-22. https://doi.org/10.1037/1082-989X.12.1.1

Enders, C. K., \& Bandalos, D. L. (2001). The relative performance of full information maximum likelihood estimation for missing data in structural equation models. Structural Equation Modeling, 8, 430-457. https://doi.org/10.1207/ S15328007SEM0803_5

Epitropaki, O., \& Martin, R. (2004). Implicit leadership theories in applied settings: Factor structure, generalizability, and stability over time. Journal of Applied Psychology, 89, 293-310. https://doi.org/10.1037/0021-9010.89.2.293

Ericsson, K. A., \& Lehmann, A. C. (1996). Expert and exceptional performance: Evidence of maximal adaptation to task constraints. Annual Review of Psychology, 47, 273-305. https://doi.org/10.1146/annurev.psych.47.1.273

Ernst, H., Leptein, C., \& Vitt, J. (2000). Inventors are not alike: The distribution of patenting output among industrial R\&D personnel. IEEE Transactions on Engineering Management, 47, 184-199. https://doi.org/10.1109/17.846786

Felps, W., Mitchell, T. R., Hekman, D. R., Lee, T. W., Holtom, B. C., \& Harman, W. S. (2009). Turnover contagion: How coworkers' job embeddedness and job search behaviors influence quitting. Academy of Management Journal, 52, 545-561. https://doi. org/10.5465/amj.2009.41331075

Ferris, D. L., Lian, H., Brown, D. J., \& Morrison, R. (2015). Ostracism, self-esteem, and job performance: When do we self-verify and when do we self-enhance?. Academy of Management Journal, 58, 279-297. https://doi.org/10.5465/amj.2011.0347

Ferris, D. L., Spence, J. R., Brown, D. J., \& Heller, D. (2012). Interpersonal justice and workplace deviance: The role of esteem threat. Journal of Management, 38, 1788-1811. https://doi.org/10.1177/0149206310372259

Fishbein, M. (1966). The relationships between beliefs, attitudes and behavior. In S. Feldman, (Ed.), Cognitive consistency, motivational antecedents and behavioral consequents, pp. 199-223. Academic.

Fisher, C. D. (1980). On the dubious wisdom of expecting job satisfaction to correlate with performance. Academy of Management Review, 5(4), 607-612. https://doi.org/10.5465/amr.1980.4288967

French, J. R. P., \& Raven B.. (1959). The bases of social power. In D. Cartwright, (Ed.), Studies in social power (pp. 150-167). Institute for Social Research.

Giesler, R. B., Josephs, R. A., \& Jr S., \& W, B. (1996). Self-verification in clinical depression: The desire for negative evaluation. Journal of Abnormal Psychology, 105, 358-368. https://doi.org/10.1037/0021-843X.105.3.358

Griffeth, R. W., Hom, P. W., \& Gaertner, S. (2000). A meta-analysis of antecedents and correlates of employee turnover: Update, moderator tests, and research implications for the next millennium. Journal of Management, 26, 463-488. https://doi.org/ $10.1177 / 014920630002600305$

Groysberg, B., \& Lee, L. E. (2010). Star power: colleague quality and turnover. Industrial and Corporate Change, 19, 741-765. https://doi.org/10.1093/icc/dtp049

Harter, S. (1993). Causes and consequences of low self-esteem in children and adolescents. In Self-esteem (pp. 87-116). Springer. 
Higgins, E. T. (1997). Beyond pleasure and pain. American Psychologist, 52, 1280-1300. https://doi.org/10.1037/0003-066X. 52.12 .1280

Hixon, J. G., \& Swann, W. B. (1993). When does introspection bear fruit? Self-reflection, self-insight, and interpersonal choices. Journal of Personality and Social Psychology, 64, 35-43.

Hollenbeck, J. R. (2008). The role of editing in knowledge development: Consensus shifting and consensus creation. In Y. Baruch, A. M. Konrad, H. Aguinus \& W. H. Starbuck (Eds.), Journal editing: Opening the black box (pp. 16-26). Jossey Bass.

Hom, P. W., Mitchell, T. R., Lee, T. W., \& Griffeth, R. W. (2012). Reviewing employee turnover: Focusing on proximal withdrawal states and an expanded criterion. Psychological Bulletin, 138, 831-858. https://doi.org/10.1037/a0027983

Hu, L. T., \& Bentler, P. M. (1999). Cutoff criteria for fit indexes in covariance structure analysis: Conventional criteria versus new alternatives. Structural Equation Modeling, 6, 1-55. https://doi.org/10.1080/10705519909540118

Hull, C. L. (1943). Principles of behavior. New York: Appleton-Century-Crofts.

Johnson, P. O., \& Neyman, J. (1936). Tests of certain linear hypotheses and their application to some educational problems. Statistical Research Memoirs, 1, 57-93.

Jones, S. C. (1973). Self and interpersonal evaluations: Esteem theories versus consistency theories. Psychological Bulletin, 79 , 185-199. https://doi.org/10.1037/h0033957

Judge, T. A., \& Bono, J. E. (2001). Relationship of core self-evaluations traits-self-esteem, generalized self-efficacy, locus of control, and emotional stability-with job satisfaction and task performance: A meta-analysis. Journal of Applied Psychology, 86, 80-92. https://doi.org/10.1037//0021-9010.86.1.80

Judge, T. A., Bono, J. E., \& Locke, E. A. (2000). Personality and job satisfaction: The mediating role of job characteristics. Journal of Applied Psychology, 85, 237-249. https://doi.org/10.1037//0021-9010.85.2.237

Katz, J., Beach, S. R., \& Anderson, P. (1996). Self-enhancement versus self-verification: Does spousal support always help?. Cognitive Therapy and Research, 20, 345-360. https://doi.org/10.1007/BF02228038

Kernan, M. C., Watson, S., Chen, F. F., \& Kim, T. G. (2011). How cultural values affect the impact of abusive supervision on worker attitudes. Cross Cultural Management: An International Journal, 18, 464-484. https://doi.org/10.1108/13527601111179528

Khan, A. K., Moss, S., Quratulain, S., \& Hameed, I. (2018). When and how subordinate performance leads to abusive supervision: A social dominance perspective. Journal of Management, 44, 2801-2826. https://doi.org/10.1177/0149206316653930

Klotz, A. C., He, W., Yam, K. C., Bolino, M. C., Wei, W., \& Houston III, L. (2018). Good actors but bad apples: Deviant consequences of daily impression management at work. Journal of Applied Psychology, 103, 1145-1154. https://doi.org/10.1037/ apl0000335

Koch, T., Schultze, M., Burrus, J., Roberts, R. D., \& Eid, M. (2015). A multilevel CFA-MTMM model for nested structurally different methods. Journal of Educational and Behavioral Statistics, 40(5), 477-510. https://doi.org/10.3102/1076998615606109

Koopman, J., Scott, B. A., Matta, F. K., Conlon, D. E., \& Dennerlein, T. (2019). Ethical leadership as a substitute for justice enactment: An information-processing perspective. Journal of Applied Psychology, 104, 1103-1116. https://doi.org/10.1037/ apl0000403

Kristof-Brown, A. L., Zimmerman, R. D., \& Johnson, E. C. (2005). Consequences of individuals' fit at work: A meta-analysis of person-job, person-organization, person-group, and person-supervisor fit. Personnel Psychology, 58(2), $281-342$.

Kwang, T., \& Jr S., \& W, B. (2010). Do people embrace praise even when they feel unworthy? A review of critical tests of self-enhancement versus self-verification. Personality and Social Psychology Review, 14, 263-280. https://doi.org/10.1177/ 1088868310365876

Kwon, K., \& Rupp, D. E. (2013). High-performer turnover and firm performance: The moderating role of human capital investment and firm reputation. Journal of Organizational Behavior, 34, 129-150. https://doi.org/10.1002/job.1804

Lanaj, K., Kim, P. H., Koopman, J., \& Matta, F. K. (2018). Daily mistrust: A resource perspective and its implications for work and home. Personnel Psychology, 71(4), 545-570. https://doi.org/10.1111/peps.12268

Leary, M. R. (1990). Responses to social exclusion: Social anxiety, jealousy, loneliness, depression, and low self-esteem. Journal of Social and Clinical Psychology, 9, 221-229. https://doi.org/10.1521/jscp.1990.9.2.221

Leary, M. R. (2006). To what extent is self-esteem influenced by interpersonal as compared with intrapersonal processes? What are these processes? In M. Kernis (Ed.), Self-esteem issues and answers: A sourcebook of current perspectives (pp. 195-200). Psychology Press.

Leary, M. R., \& Baumeister, R. F. (2000). The nature and function of self-esteem: Sociometer theory. In Advances in experimental social psychology (Vol. 32, pp. 1-62). Academic Press.

Leary, M. R., \& Downs, D. L. (1995). Interpersonal functions of the self-esteem motive. In Efficacy, agency, and self-esteem (pp. 123-144). Springer.

Lecky, P. (1945). Self-consistency; a theory of personality. Island Press.

Lepak, D. P., \& Snell, S. A. (1999). The human resource architecture: Toward a theory of human capital allocation and development. Academy of Management Review, 24, 31-48. https://doi.org/10.2307/259035

Lee, T. W., Burch, T. C., \& Mitchell, T. R. (2014). The story of why we stay: A review of job embeddedness. Annual Review of Organizational Psychology and Organizational Behavior, 1, 199-216. https://doi.org/10.1146/annurev-orgpsych-031413-091244 
Lin, W., Wang, L., \& Chen, S. (2013). Abusive supervision and employee well-being: The moderating effect of power distance orientation. Applied Psychology: An International Review, 62, 308-329. https://doi.org/10.1111/j.1464-0597.2012.00520.x

Little, T. D., Rhemtulla, M., Gibson, K., \& Schoemann, A. M. (2013). Why the items versus parcels controversy needn't be one. Psychological Methods, 18, 285-300. https://doi.org/10.1037/a0033266

Liu, D., Liao, H., \& Loi, R. (2012). The dark side of leadership: A three-level investigation of the cascading effect of abusive supervision on employee creativity. Academy of Management Journal, 55, 1187-1212. https://doi.org/10.5465/amj.2010. 0400

Locke, E. A. (1969). What is job satisfaction?. Organizational Behavior and Human Performance, 4, 309-336.

Masciuch, S. W., McRae, L. S. E., \& Young, J. D. - (1990). The Harter Self-perception profile: Some normative and psychometric data. Psychological Reports, 67, 1299-1303. https://doi.org/10.2466/pr0.1990.67.3f.1299

Mackey, J. D., Frieder, R. E., Brees, J. R., \& Martinko, M. J. (2017). Abusive supervision: A meta-analysis and empirical review. Journal of Management, 43, 1940-1965. https://doi.org/10.1177/0149206315573997

Marsh, H. W. (1993). The multidimensional structure of academic self-concept: Invariance over gender and age. American Educational Research Journal, 30, 841-460.

Marsh, H. W., Byrne, B. M., \& Yeung, A. S. (1999). Causal ordering of academic self-concept and achievement: Reanalysis of a pioneering study and.... Educational Psychologist, 34, 155-167. https://doi.org/10.1207/s15326985ep3403_2

Marsh, H. W., Craven, R. G., \& Martin, A. (2006). What is the nature of self-esteem? Unidimensional and multidimensional perspectives. In M. Kernis (Ed.), Self-esteem: Issues and answers (pp. 16-25). Psychology Press.

Matta, F. K., Scott, B. A., Koopman, J., \& Conlon, D. E. (2015). Does seeing "eye to eye" affect work engagement and organizational citizenship behavior? A role theory perspective on LMX agreement. Academy of Management Journal, 58, 1686-1708. https://doi.org/10.5465/amj.2014.0106

Mayer, D. M., Thau, S., Workman, K. M., Van Dijke, M., \& De Cremer, D. (2012). Leader mistreatment, employee hostility, and deviant behaviors: Integrating self-uncertainty and thwarted needs perspectives on deviance. Organizational Behavior and Human Decision Processes, 117, 24-40. https://doi.org/10.1016/j.obhdp.2011.07.003

McClean, S. T., Courtright, S. H., Yim, J., \& Smith, T. A. (2021). Making nice or faking nice? Exploring supervisors' two-faced response to their past abusive behavior. Personnel Psychology, 1-27. https://doi.org/10.1111/peps.12424

Merz, E. L., Malcarne, V. L., Roesch, S. C., Ko, C. M., Emerson, M., Roma, V. G., \& Sadler, G. R. (2013). Psychometric properties of Positive and Negative Affect Schedule (PANabusive supervision) original and short forms in an African American community sample. Journal of Affective Disorders, 151, 942-949. https://doi.org/10.1016/j.jad.2013.08.011

Messersmith, J. G., \& Guthrie, J. P. (2010). High performance work systems in emergent organizations: Implications for firm performance. Human Resource Management, 49, 241-264. https://doi.org/10.1002/hrm.20342

Mitchell, M. S., \& Ambrose, M. L. (2007). Abusive supervision and workplace deviance and the moderating effects of negative reciprocity beliefs. Journal of Applied Psychology, 92, 1159-1168. https://doi.org/10.1037/0021-9010.92.4.1159

Mitchell, T. R., Holtom, B. C., Lee, T. W., Sablynski, C. J., \& Erez, M. (2001). Why people stay: Using job embeddedness to predict voluntary turnover. Academy of Management Journal, 44(6), 1102-1121. https://doi.org/10.5465/3069391

Mitchell, T. R., \& Lee, T. W. (2001). The unfolding model of voluntary turnover and job embeddedness: Foundations for a comprehensive theory of attachment. Research in Organizational Behavior, 23, 189-246.

Molleman, E., Nauta, A., \& Buunk, B. P. (2007). Social comparison-based thoughts in groups: Their associations with interpersonal trust and learning outcomes. Journal of Applied Social Psychology, 37, 1163-1180. j.1559-1816.2007.00207.x

Mruk, C. J. (2006). Self-esteem research, theory, and practice: Toward a positive psychology of self-esteem. Springer Publishing Company.

Murray, S. L., Holmes, J. G., \& Griffin, D. W. (2000). Self-esteem and the quest for felt security: How perceived regard regulates attachment processes. Journal of Personality and Social Psychology, 78, 478-498. https://doi.org/10.1037/0022-3514.78.3. 478

Neeman, J., \& Harter, S. (1986). Manual for the self-perception profile for college students. Denver, CO: University of Denver Press.

Nyberg, A. (2010). Retaining your high performers: Moderators of the performance-job satisfaction-voluntary turnover relationship. Journal of Applied Psychology, 95, 440-453. https://doi.org/10.1037/a0018869

Ogunfowora, B. (2013). When the abuse is unevenly distributed: The effects of abusive supervision variability on work attitudes and behaviors. Journal of Organizational Behavior, 34(8), 1105-1123. https://doi.org/10.1002/job.1841

Oldroyd, J. B., \& Morris, S. S. (2012). Catching falling stars: A human resource response to social capital's detrimental effect of information overload on star employees. Academy of Management Review, 37, 396-418. https://doi.org/10.5465/amr.2010. 0403

Peter, L. J., \& Hull, R. (1969). The peter principle (No. 04; RMD, PN6231. M2 P4.). Souvenir Press.

Pierce, J. L., \& Gardner, D. G. (2004). Self-esteem within the work and organizational context: A review of the organizationbased self-esteem literature. Journal of Management, 30, 591-622. https://doi.org/10.1016/j.jm.2003.10.001

Pierce, J. L., Gardner, D. G., Cummings, L. L., \& Dunham, R. B. (1989). Organization-based self-esteem: Construct definition measurement and validation. Academy of Management Journal, 32, 622-648. https://doi.org/10.5465/256437 
Podsakoff, P. M., MacKenzie, S. B., Lee, J. Y., \& Podsakoff, N. P. (2003). Common method biases in behavioral research: a critical review of the literature and recommended remedies. Journal of Applied Psychology, 88, 879-903. https://doi.org/10.1037/ 0021-9010.88.5.879

Porter, L. W. \& Steers, R. M. (1973). Organizational, work, and personal factors in employee turnover and absenteeism. Psychological Bulletin, 80, 151-176. https://doi.org/10.1037/h0034829

Preacher, K. J., \& Selig, J. P. (2012). Advantages of Monte Carlo confidence intervals for indirect effects. Communication Methods and Measures, 6, 77-98. https://doi.org/10.1080/19312458.2012.679848

Ritts, V., \& Stein, J. R. (1995). Verification and commitment in marital relationships: An exploration of self-verification theory in community college students. Psychological Reports, 76, 383-386. https://doi.org/10.2466/pr0.1995.76.2.383

Rosen, C. C., Dimotakis, N., Cole, M. S., Taylor, S. G., Simon, L. S., Smith, T. A., \& Reina, C. S. (2020). When challenges hinder: An investigation of when and how challenge stressors impact employee outcomes. Journal of Applied Psychology, https://doi. org/10.1037/apl0000483

Rubin, D. B., \& Little, R. J. A. (2002). Statistical analysis with missing data (Wiley series in probability and Statistics) (2nd ed.). John Wiley \& Sons.

Sacco, W. P., \& Phares, V. (2001). Partner appraisal and marital satisfaction: The role of self-esteem and depression. Journal of Marriage and Family, 63, 504-513. https://doi.org/10.1111/j.1741-3737.2001.00504.x

Schleicher, D. J., Smith, T. A., Casper, W. J., Watt, J. D., \& Greguras, G. J. (2015). It's all in the attitude: The role of job attitude strength in job attitude-outcome relationships. Journal of Applied Psychology, 100, 1259-1274. https://doi.org/10.1037/ a0038664

Scott, K. D., \& Taylor, G. S. (1985). An examination of conflicting findings on the relationship between job satisfaction and absenteeism: A meta-analysis. Academy of Management Journal, 28, 599-612.

Shrauger, J. S. (1975). Responses to evaluation as a function of initial self-perceptions. Psychological Bulletin, 82, 581-596. https://doi.org/10.1037/h0076791

Sinacore-Guinn, A. L. (1998). Employed mothers: Job satisfaction and self-esteem. Canadian Journal of Counselling, 32, $242-58$.

Solomon, S., Greenberg, J., \& Pyszczynski, T. (1991). A terror management theory of social behavior: The psychological functions of self-esteem and cultural worldviews. In Advances in experimental social psychology (Vol. 24, pp. 93-159). Academic Press.

Steers, R. M., \& Mowday, R. W. (1981). Employee turnover and postdecision accommodation processes. In L. L. Cummings \& B. M. Staw (Eds.), Research in organizational behavior (pp. 235-281). JAI Press.

Stumpf, S. A., \& Dawley, P. K. (1981). Predicting voluntary and involuntary turnover using absenteeism and performance indices. Academy of Management Journal, 24(1), 148-163. https://doi.org/10.5465/255830

Swann, W. B. (1983). Self-verification: Bringing social reality into harmony with the self. Social Psychological Perspectives on the Self. Erlbaum.

Swann, W. B. (2005). The self and identity negotiation. Interaction Studies, 6, 69-83.

Swann, W. B., \& Brooks, M. (2012). Why threats trigger compensatory reactions: The need for coherence and quest for selfverification. Social Cognition, 30, 758-777. https://doi.org/10.1521/soco.2012.30.6.758

Swann, W. B., \& Buhrmester, M. D. (2012). Self as functional fiction. Social Cognition, 30, 415-430. https://doi.org/10.1521/ soco.2012.30.4.415

Swann, W. B., \& Hill, C. A. (1982). When our identities are mistaken: Reaffirming self-conceptions through social interaction. Journal of Personality and Social Psychology, 43, 59-66. https://doi.org/10.1037/0022-3514.43.1.59

Swann Jr, W. B., Pelham, B. W., \& Krull, D. S. (1989). Agreeable fancy or disagreeable truth? Reconciling self-enhancement and self-verification. Journal of Personality and Social Psychology, 57, 782-791. Doi:

Swann, W. B., Polzer, J. T., Seyle, D. C., \& Ko, S. J. (2004). Finding value in diversity: Verification of personal and social self-views in diverse groups. Academy of Management Review, 29, 9-27. https://doi.org/10.5465/amr.2004.11851702

Swann, W. B. Jr., Rentfrow, P. J., \& Guinn, J. (2002). Self-verification: The search for coherence. In M. Leary \& J. Tagney (Eds.), Handbook of self and identity (pp. 367-383). Guilford Press.

Swann, W. B., Stein-Seroussi, A., \& Giesler, R. B. (1992). Why people self-verify. Journal of Personality and Social Psychology, 62, 392-401. https://doi.org/10.1037/0022-3514.62.3.392

Swider, B. W., Boswell, W. R., \& Zimmerman, R. D. (2011). Examining the job search-turnover relationship: The role of embeddedness, job satisfaction, and available alternatives. Journal of Applied Psychology, 96(2), 432-441. https://doi.org/10.1037/ a0021676

Talaifar, S., \& Swann, W. B. (2020). Self-verification theory. In Zeigler-Hill V., Shackelford T. (Eds.), Encyclopedia of personality and individual differences. Springer.

Talaifar, S., Buhrmester, M. D., Ayduk, O., \& Swann, W. B. (in press). Asymmetries in mutual understanding: People with low status, power, and self-esteem understand better than they are understood. Perspectives on Psychological Science.

Tepper, B. J. (2000). Consequences of abusive supervision. Academy of Management Journal, 43, 178-190. https://doi.org/10. $5465 / 1556375$ 
Tepper, B. J. (2007). Abusive supervision in work organizations: Review, synthesis, and research agenda. Journal of Management, 33, 261-289. https://doi.org/10.1177/0149206307300812

Tepper, B. J., Carr, J. C., Breaux, D. M., Geider, S., Hu, C., \& Hua, W. (2009). Abusive supervision, intentions to quit, and employees' workplace deviance: A power/dependence analysis. Organizational Behavior and Human Decision Processes, 109, 156167. https://doi.org/10.1016/j.obhdp.2009.03.004

Tepper, B. J., Dimotakis, N., Lambert, L. S., Koopman, J., Matta, F. K., Man Park, H., \& Goo, W. (2018). Examining follower responses to transformational leadership from a dynamic, person-environment fit perspective. Academy of Management Journal, 61, 1343-1368. https://doi.org/10.5465/amj.2014.0163

Tepper, B. J., Moss, S. E., \& Duffy, M. K. (2011). Predictors of abusive supervision: Supervisor perceptions of deep-level dissimilarity, relationship conflict, and subordinate performance. Academy of Management Journal, 54, 279-294. https://doi.org/ 10.5465/amj.2011.60263085

Thatcher, S. M., \& Zhu, X. (2006). Changing identities in a changing workplace: Identification, identity enactment, selfverification, and telecommuting. Academy of Management Review, 31, 1076-1088. https://doi.org/10.5465/amr.2006. 22528174

Thau, S., \& Mitchell, M. S. (2010). Self-gain or self-regulation impairment? Tests of competing explanations of the supervisor abuse and employee deviance relationship through perceptions of distributive justice. Journal of Applied Psychology, 95(6), 1009-1031. https://doi.org/10.1037/a0020540

Tracy, J. L., \& Robins, R. W. (2004). Show your pride: Evidence for a discrete emotion expression. Psychological Science, 15, 194197. https://doi.org/10.1111/j.0956-7976.2004.01503008.x

Trevor, C. O., Hausknecht, J. P., \& Howard, M. J. (2007). Why high and low performers leave and what they find elsewhere: Job performance effects on employment transitions [CAHRS Working Paper Series]. 466.

Tu, M. H., Bono, J. E., Shum, C., \& LaMontagne, L. (2018). Breaking the cycle: The effects of role model performance and ideal leadership self-concepts on abusive supervision spillover. Journal of Applied Psychology, 103, 689-702. https://doi.org/10. 1037/apl0000297

Tzabbar, D. (2009). When does scientist recruitment affect technological repositioning?. Academy of Management Journal, 52, 873-896. https://doi.org/10.5465/amj.2009.44632853

Vogel, R. M., \& Mitchell, M. S. (2017). The motivational effects of diminished self-esteem for employees who experience abusive supervision. Journal of Management, 43, 2218-2251. https://doi.org/10.1177/0149206314566462

Volmer, J., Niessen, C., Spurk, D., Linz, A., \& Abele, A. E. (2011). Reciprocal relationships between leader-member exchange (LMX) and job satisfaction: A cross-lagged analysis. Applied Psychology, 60, 522-545. https://doi.org/10.1111/j.1464-0597. 2011.00446.x

Vroom, V. H. (1964). Work and motivation (Vol., 54). Wiley.

Wang, G., Harms, P. D., \& Mackey, J. D. (2015). Does it take two to tangle? Subordinates' perceptions of and reactions to abusive supervision. Journal of Business Ethics, 131, 487-503. https://doi.org/10.1007/s10551-014-2292-7

Watson, D., \& Clark, L. A. (1994). The PANAS-X: manual for the positive and negative.

Webster, M., \& Sobieszek, B. (1974). Sources of self-evaluation: A formal theory of significant others and social influence. John Wiley $\&$ Sons.

West, S. G., Taylor, A. B., \& Wu, W. (2012). Model fit and model selection in structural equation modeling. Handbook of Structural Equation Modeling, 1, 209-231.

Wiesenfeld, B. M., Swann Jr, W. B., Brockner, J., \& Bartel, C. A. (2007). Is more fairness always preferred? Self-esteem moderates reactions to procedural justice. Academy of Management Journal, 50, 1235-1253. https://doi.org/10.2307/20159922

Williams, L. J., \& Anderson, S. E. (1991). Job satisfaction and organizational commitment as predictors of organizational citizenship and in-role behaviors. Journal of Management, 17, 601-617. https://doi.org/10.1177/014920639101700305

Williams, L. J., \& O'Boyle Jr, E. H. (2008). Measurement models for linking latent variables and indicators: A review of human resource management research using parcels. Human Resource Management Review, 18, 233-242. https://doi.org/10.1016/ j.hrmr.2008.07.002

Williams, L. J., O'Boyle, E. H., \& Yu, J. (2020). Condition 9 and 10 tests of model confirmation: A review of James, Mulaik, and Brett (1982) and contemporary alternatives. Organizational Research Methods, 23, 6-29. https://doi.org/10.1177/ 1094428117736137

Wright, P. M., \& McMahan, G. C. (1992). Theoretical perspectives for strategic human resource management. Journal of Management, 18, 295-320. https://doi.org/10.1177/014920639201800205

How to cite this article: Smith, T. A., Boulamatsi, A., Dimotakis, N., Tepper, B. J., Runnalls, B. A., Reina, C. S., \& Lucianetti, L. (2022). "How dare you?!": A self-verification perspective on how performance influences the effects of abusive supervision on job embeddedness and subsequent turnover. Personnel Psychology, 1-30. Advance online publication. https://doi.org/10.1111/peps.12494 